\title{
Building Vintage and Electricity Use: Old Homes Use Less Electricity in Hot Weather
}

\author{
Howard Chong, Cornell University
}

\begin{abstract}
This paper studies whether electricity use in newer or older residential buildings rises more in response to high temperature in a region of Southern California. Peak electricity demand occurs at the highest temperatures which are predicted to increase due to climate change. Understanding how newer buildings differ from older buildings improves forecasts of how peak electricity use will grow over time. Newer buildings are subject to stricter building energy codes, but are larger and more likely to have air conditioning; hence, the cumulative effect is ambiguous. This paper combines four large datasets of building and household characteristics, weather data, and utility data to estimate the electricity-temperature response of different building vintages. Estimation results show that new buildings (1970-2000) have a statistically significantly higher temperature response (i.e., use more electricity) than old buildings (pre1970). Auxiliary regressions with controls for tiered electricity prices, number of bedrooms, income, square footage, central air conditioning, ownership, and type of residential structure partially decompose the effect. Though California has had extensive energy efficiency building standards that by themselves would lower temperature response for new buildings, the cumulative effect of new buildings is an increase in temperature response. As new buildings are added, aggregate temperature response is predicted to increase.
\end{abstract}

\section{Introduction}

Understanding the relationship between electricity usage and temperature, i.e., temperature response, is important for climate change policy and long-range electricity infrastructure planning. Residential buildings are a substantial contributor to $\mathrm{CO} 2$ emissions. In the US, residential buildings account for $21 \%$ of 2008 CO2 emissions (Environmental Protection Agency, 2010), with about 50\% of residential energy going to space heating and air conditioning (Energy Information Administration, 2009). Furthermore, temperature increases from CO2 emissions will affect electricity demand through 
increased cooling loads, i.e., air conditioning use. Electric power plant construction and infrastructure decisions are strongly driven by peak electricity demand which in California occurs during periods of highest temperature.

If new buildings have higher temperature response, ${ }^{1}$ then the average temperature response will increase as new buildings are added. Peak demand per household will also increase. Policies to reduce greenhouse gas emissions or reduce energy use often aim to decrease peak and total electricity demand.

Temperature response is better than total electricity use as a measure of the performance of buildings. As the component of electricity usage that varies with temperature, temperature response isolates factors such as the thermal performance of the building, the size of the building, and the thermostat preferences of occupants. In contrast, total electricity use conflates these factors with appliance ownership (e.g., more televisions) and other factors that do not depend on the building. ${ }^{2}$

Whether newer or older the residential buildings in California have higher temperature response which has not been studied using field data. California has had the most extensive energy efficiency standards in the United States applied to new buildings. Engineering models (e.g., Marshall and Gorin, 2007; Abrishami et al., 2005), predict strong reductions in energy use (both peak and total use) due to these standards, ceteris paribus, but other factors can offset these improvements. The sign of the cumulative effect, measured as the difference between new and old buildings, is ambiguous. I use field data to estimate the temperature response across houses of different vintages.

This paper uses (household, monthly) field panel data on electricity use linked to building vintage and other building and household characteristics. Household electricity usage (quantity) data in Riverside County, California, USA, is regressed on time series variation in temperature to estimate temperature response. Cross sectional variation in building vintage and other characteristics at the ZIP9level or census block group-level identifies the temperature response by vintage.

The main finding is that each successive decade since 1970 has statistically significantly increased temperature response compared to older buildings (built prior to 1970). Hence, average peak load is expected to increase due to population growth and ensuing new construction. This exacerbates the impact of climate change on electricity use. Auxiliary regressions add controls for bedrooms,

\footnotetext{
${ }^{1}$ In this paper, temperature response is defined as the percentage increase (relative to usage on a $65^{\circ} \mathrm{F}$ day) in electricity use due to a $1^{\circ} \mathrm{F}$ increase in temperature. Higher temperature response means more incremental electricity use.

${ }^{2}$ Though I focus on temperature response, I also present comparisons of the total electricity use across vintage in Appendix A. Unsurprisingly, new homes use more electricity, principally because they are larger.
} 
income, sqft, central air conditioning ownership, and type of residential structure. These covary with vintage and partially explain the increase in temperature response for newer buildings. ${ }^{3}$

The organization of the paper is as follows. Section 2 presents existing related studies. Section 3 presents a description of the data. Section 4 presents the econometric models and underlying assumptions. Section 5 estimates the models. Section 6 discusses results and potential mechanisms. Section 7 concludes.

\section{Related Work}

Temperature Response and Building Vintage in Field Evidence and Forecasting

Several papers have focused on temperature response of buildings using field evidence but have ignored how buildings have changed across vintage. Aroonruengsawat and Auffhammer (2009) examined the variation in the nonlinear relationship between temperature and electricity use by 16 climate zones in California, showing that the strongest relationships are in hotter inland areas. Earlier work on temperature response with (annual, state)-level data by Deschênes and Greenstone (2011) predicted that climate change scenarios generate a $33 \%$ increase in residential energy consumption nationwide with the current set of buildings. New buildings, if they perform worse than older buildings, may exacerbate this predicted increase.

By ignoring vintage effects, such studies would underestimate the impact of new buildings. Baxter and Calandri (1992) use an engineering model to estimate the impact of a $1.9^{\circ} \mathrm{C}$ temperature increase, finding a $2-4 \%$ increase in electricity use, but the study holds the building stock fixed. More recent work suggests that newer buildings are more temperature responsive. Every two years, the California Energy Commission runs a detailed simulation model to construct its demand forecast that includes a large mix of econometrically estimated parameters and engineering estimates. In a recent revision, they find that air conditioning saturation for newer buildings increased unexpectedly for both hotter (inland) and cooler (coastal) areas (Marshall and Gorin, 2007). ${ }^{4}$

\footnotetext{
${ }^{3}$ In most specifications, newer homes have statistically significantly higher temperature response. In the most unrestrictive specification (see Appendix B) which has less statistical precision, 1990s homes are estimated to have a temperature response of $8 \%$ less to $6 \%$ more than pre 1970 s homes.

${ }^{4}$ Their large simulation model does not directly report temperature response. Instead, they report a related statistic, load factor, which is defined as average demand relative to peak demand. Load factor and average temperature response are inversely related. They project that load factor will decrease suggesting that newer homes should have higher temperature response.
} 
A limitation of engineering studies is uncertainty about whether engineering parameters represent actual field performance. Joskow and Marron (1992) describe many factors that contribute to overstatement of program effectiveness. First, a rebound effect may exist where occupants demand more services by responding to a decrease in the price due to efficiency (Greening et al., 2000). Also, interventions may imperfectly translate from the lab to the field or unexpected confounding effects could diminish or accentuate savings. Although only a small portion of their broader critique, Joskow and Marron highlight the difficulty of extrapolating from the laboratory to the field. In Joskow and Marron (1993), they find that the ratio of measured to estimated savings are 0.31-0.42 for two 1980s retrofit programs; that is, engineering predictions overstated savings by a factor from 2 to 3 . As more current evidence that field measurements and engineering estimates differ, Larsen and Nesbakken (2004) compare an econometric decomposition approach with the predictions of engineering models in Norway. They find that the two approaches decompose end uses quite differently. Hirst (1990) surveys the broader question of program evaluation. Nadel and Keating (1991) summarize results of a large number of older field evaluations and find generally positive, but usually smaller, savings than what engineers predict. Use of field data, like that done in this paper, can produce more realistic forecasts or provide ways to validate engineering estimates. If engineering parameters overstate energy savings, then demand forecasts will be biased downward.

Two very recent papers use field data to test the impact of building vintage, both using monthly utility data. Jacobsen and Kotchen (2010) analyze one building standard code change in Florida using a sharp regression discontinuity. They estimate a 4-6\% reduction is the energy use. Costa and Kahn (2010) estimate the differences in total electricity use by building vintage for buildings in a community in California using cross-sectional variation and show that homes built after 1983 had lower total electricity use. My research looks at the differences for homes over three decades and focuses on differences in temperature response. 


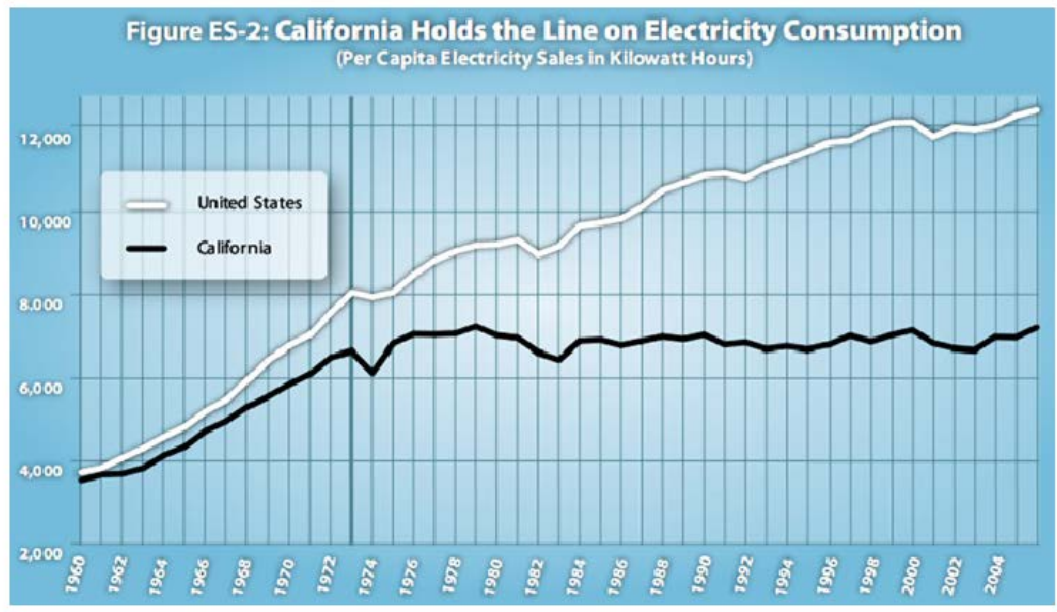

Figure 1 The "Rosenfeld" curve per capita electricity sales for California and the United States, annually from 1960 to 2006. Source: California Energy Commission (2007)

The Rosenfeld Curve and Energy Efficiency

Per capita total electricity sales for California have been relatively flat since the mid-1970s, when landmark legislation for energy efficiency was passed. Comparatively, sales for the rest of the United States have gone up by $50 \%$ (Fig. 1). Explanations of this time series phenomenon, commonly referred to as the Rosenfeld Curve, vary widely. One obvious potential explanation points to California's policies, especially the establishment of building and appliance standards unique to California, which also began in the mid 1970s. However, correlation is not causation. The visual remarkableness of this curve is tempered when looking at comparable curves for nearby states. A look at analogous "Rosenfeld Curves" of residential electricity per capita over time for eight Western States (Fig. 2) presents a quick visual contrast to California's impressive performance relative to the United States (Fig. 1). Three other states (NV, OR, and WA) have had flat residential electricity per capita profiles, though they had weaker building standards. ${ }^{5}$

Avoiding many of the problems of state-level analyses, my research uses rarely available microdata at the household- level with covariates at the 5-10 household-level. State-level analyses are problematic because they assume comparability across states. The identifying assumption in such studies is that changes in per-capita electricity load across states would have been the same in the

\footnotetext{
${ }^{5}$ Historical information for all states on building energy standards comes from the Building Codes Assistance Project (n.d.).. Nevada implemented a mandatory building energy code in 1978 but "between 1983 and 1986, the state did not support or enforce this energy code". Oregon implemented a building energy code in 1978 that did not apply to residential buildings. A residential code was adopted in 2003. Washington adopted a voluntary energy code in 1977, with a mandatory code established in 1986.
} 
absence of energy efficiency policies. This assumption is embedded in several state-level analyses: Aroonruengsawat et al. (2009) and Horowitz (2007) use state-level panel data; Sudarshan and Sweeney (2008) make a comparison between the US and California; and Loughran and Kulick (2004) and Auffhammer et al. (2008) use utility-level panel data. These analyses typically find evidence that energy efficiency programs reduce energy consumption. Comparability across states can be violated for many reasons. The evolution of a state's aggregate energy efficiency (as measured by residential electricity per capita) will depend on changes in the composition of the type of housing (urban vs rural, single family vs multifamily/mobile homes), differential growth in the size of housing, changes in geographic/ climatic composition (e.g., coastal vs inland), and differences in the adoption of air conditioning.

This analysis makes an important contribution to studies of policies aimed at reducing residential energy. In the context of "energy intensity" measures, such as electricity per capita or per GDP, my research identifies the new and counterintuitive empirical fact that households in new buildings use more electricity, both in total use and in response to temperature. It runs counter to what one might expect from looking at the Rosenfeld Curve, where per capita electricity has been flat, but the Rosenfeld Curve is an aggregate-level result that may conflate other factors. ${ }^{6}$ Explaining what causes this empirical fact is important for understanding the effectiveness of building energy use policy in the context of many simultaneous changes.

\footnotetext{
${ }^{6}$ Given that households in new buildings today use more electricity than those in older buildings today, if use in older buildings has not changed, then the average household use today would go up. Since this contradicts the flat average electricity use (Rosenfeld Curve), this implies that households in old buildings use significantly less electricity today than before, to the extent that the time series of average use is flat.
} 


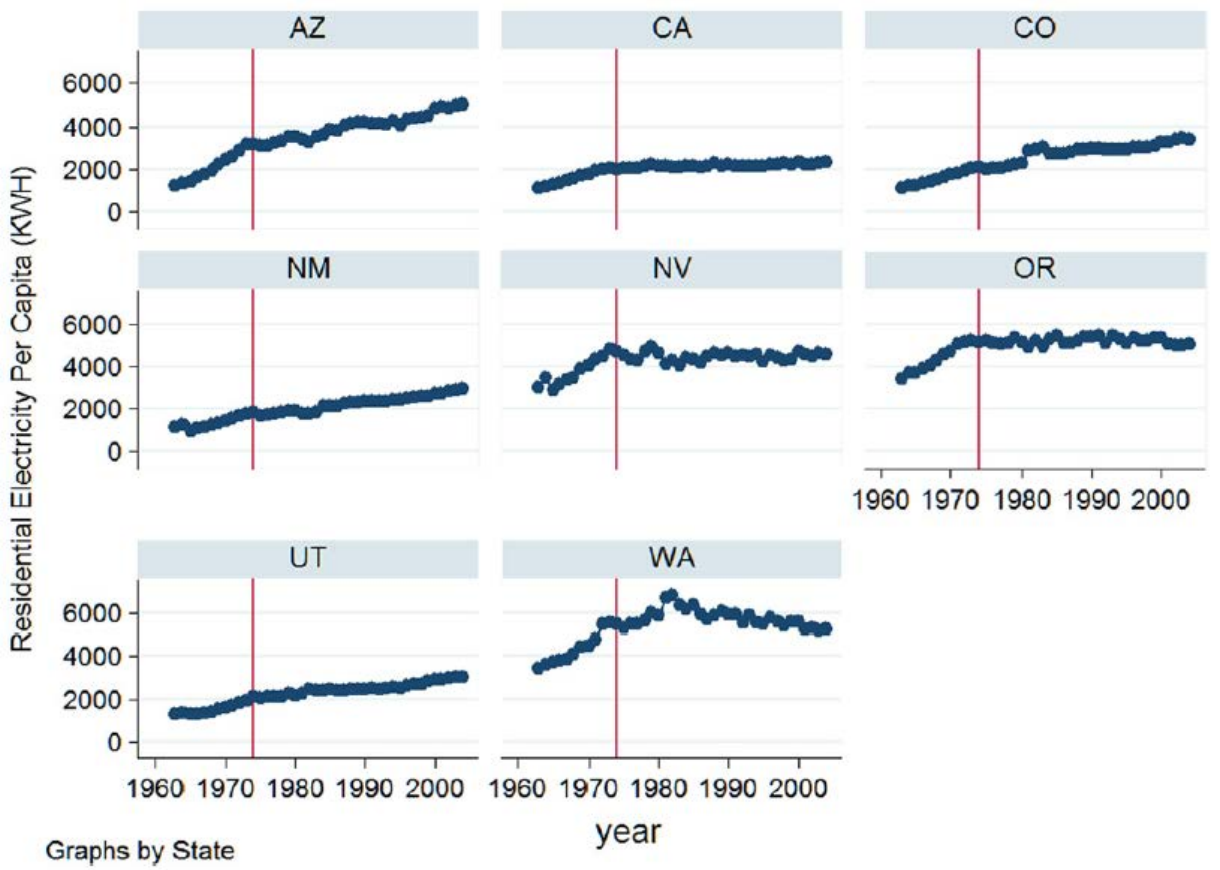

Figure 2 Per capita residential electricity sales for eight western states, 1963-2004 Source: Energy Information Administration (2007).

\section{Description of the Data}

This paper currently focuses on one county, Riverside County, where there are over 20 million observations for Southern California Edison (SCE) electric utility customers from part of 1998 to part of 2009. ${ }^{7}$ Information includes billing start date, billing end date, total electricity used (kWh), total bill, an account id, a physical location id, and the zip code (usually at the nine digit level). Riverside County was chosen for four reasons. First, it is an inland (rather than coastal) area with a wide range of temperatures. Second, there is considerable variation in the building vintage. Third, Aroonruengsawat and Auffhammer (2009) found this region to have substantial average temperature response. Fourth, detailed county assessor's property information is available. It is important to restrict to one county or area because housing design, climate, and building standards differ strongly across the state. For data cleaning, bills with 25 days or less or 35 days or more were dropped (about $5 \%$ ). Bills with less than 2 $\mathrm{kWh} /$ day or more than $80 \mathrm{kWh} /$ day are outliers were also dropped (about $4 \%){ }^{8}$

\footnotetext{
${ }^{7}$ This confidential data set, along with records for two other large investor-owned utilities, was made available to the University of California Energy Institute for research purposes.

${ }^{8}$ The main analysis was re-run with a cutoff of $200 \mathrm{kWh} /$ day rather than $80 \mathrm{kWh} /$ day. Results did not markedly change.
} 
The billing data lacks housing and household information; two data sets of different spatial resolution are used to provide this information. County assessor's data (County of Riverside Assessor's Office, 2010) was obtained for single family homes identifiable to the address. Because SCE billing includes both bills for single family and multifamily (e.g., apartments), I condition on census block groups where more than $95 \%$ of households are in single family homes. Bills are next matched to assessor data via the ZIP9. ZIP9s are very small, with an average of 4.8 assessor records per ZIP9. For each ZIP9, the proportion constructed in each vintage category, the median of square footage, and the proportion of houses with central air conditioning for each ZIP9 is associated with all the bills in that ZIP9.

The second source of housing information is the US Census. The 2000 US Census's Summary File $3^{9}$ (United States Census Bureau, 2009) has at the census block group-level proportions of the vintage of housing, proportions of type of structure (single family vs multifamily vs mobile home), the number of rooms, and the income distribution. A census block group has a size on the order of 500 housing units. Fig. 3 has a map of part of Riverside County by census tract. ${ }^{10}$ The shading corresponds to the proportion of housing in a tract that was built after 1980, with darker meaning more new construction. Hence, within this county, there is substantial spatial variation in the age of housing which is needed for estimating vintage differentiated temperature response; i.e., temperature response is compared between dark and light areas of the map. Because of the large number of observations and computing limitations, a 1-in-5 subsample was used to reduce the sample to 5.3 million observations when using census data.

Daily maximum (Tmax) and minimum (Tmin) temperature at a $4 \mathrm{~km} \times 4 \mathrm{~km}$ grid are generated according to the algorithm used by Schlenker and Roberts (2009) which has been used for estimating the relationship between crop yields and temperature. The reader is directed there for a more full description of the algorithm as well as diagnostics that show the methodology is reliable. Billing data are then matched via ZIP9 to the gridded temperature data and to the census block group. The average of Tmax and Tmin is then taken as the daily temperature. These are then translated into cooling degree days (CDD) and heating degree days (HDD) with a reference temperature of $65^{\circ} \mathrm{F}$. In a more flexible approach which follows Aroonruengsawat and Auffhammer (2009), the daily temperature is binned into 10 bins with approximately equal number of observations. Temperature bin ranges are listed in Table 1.

\footnotetext{
${ }^{9}$ This is also known as the Census Long Form.

${ }^{10}$ On average, a census tract is three census block groups.
} 


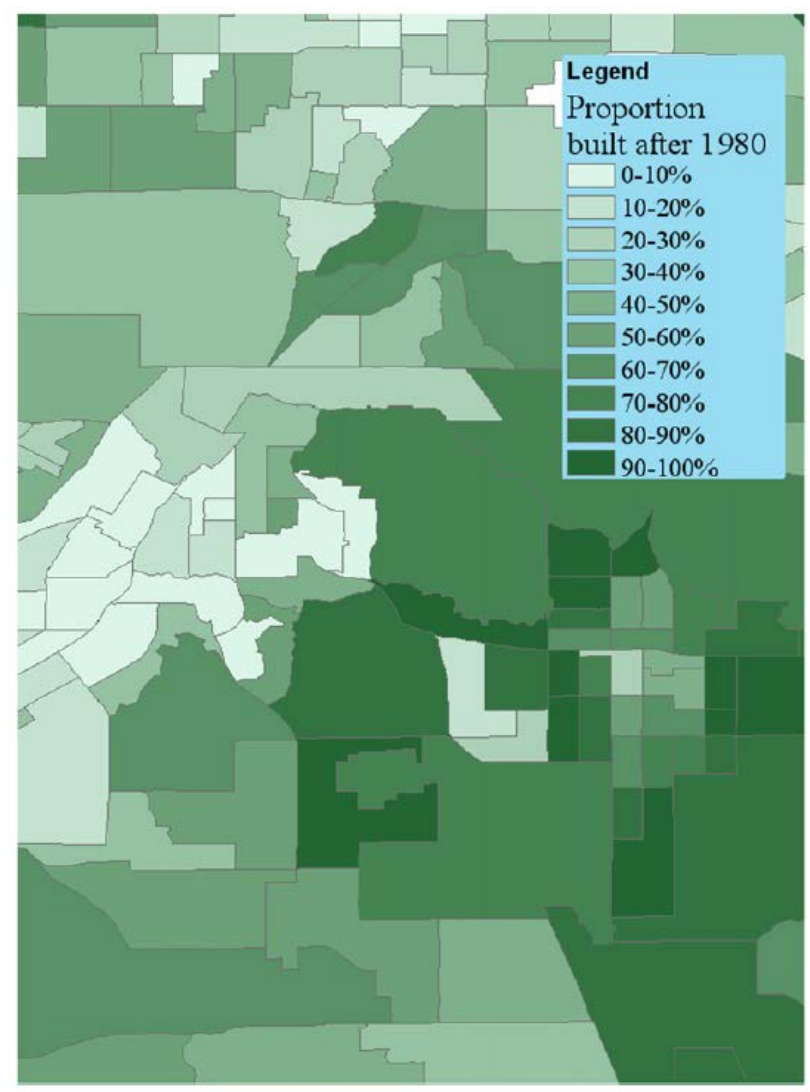

Figure 3 Variation in building vintage in Riverside County, California, USA. Shading represents proportion of buildings built since 1980. Darker means higher proportions of new buildings.

Table 1

Temperature bins.

\begin{tabular}{ll}
\hline Bin number & Temperature range $\left({ }^{\circ} \mathrm{F}\right)$ \\
\hline bin0 & $0-51.96$ \\
bin1 & $51.96-55.89$ \\
bin2 & $55.89-59.25$ \\
bin3 & $59.25-62.70$ \\
bin4 & $62.70-66.39$ \\
bin5 & $66.39-70.54$ \\
bin6 & $70.54-74.37$ \\
bin7 & $74.37-78.30$ \\
bin8 & $78.30-84.02$ \\
bin9 & $84.02-130$ \\
\hline
\end{tabular}




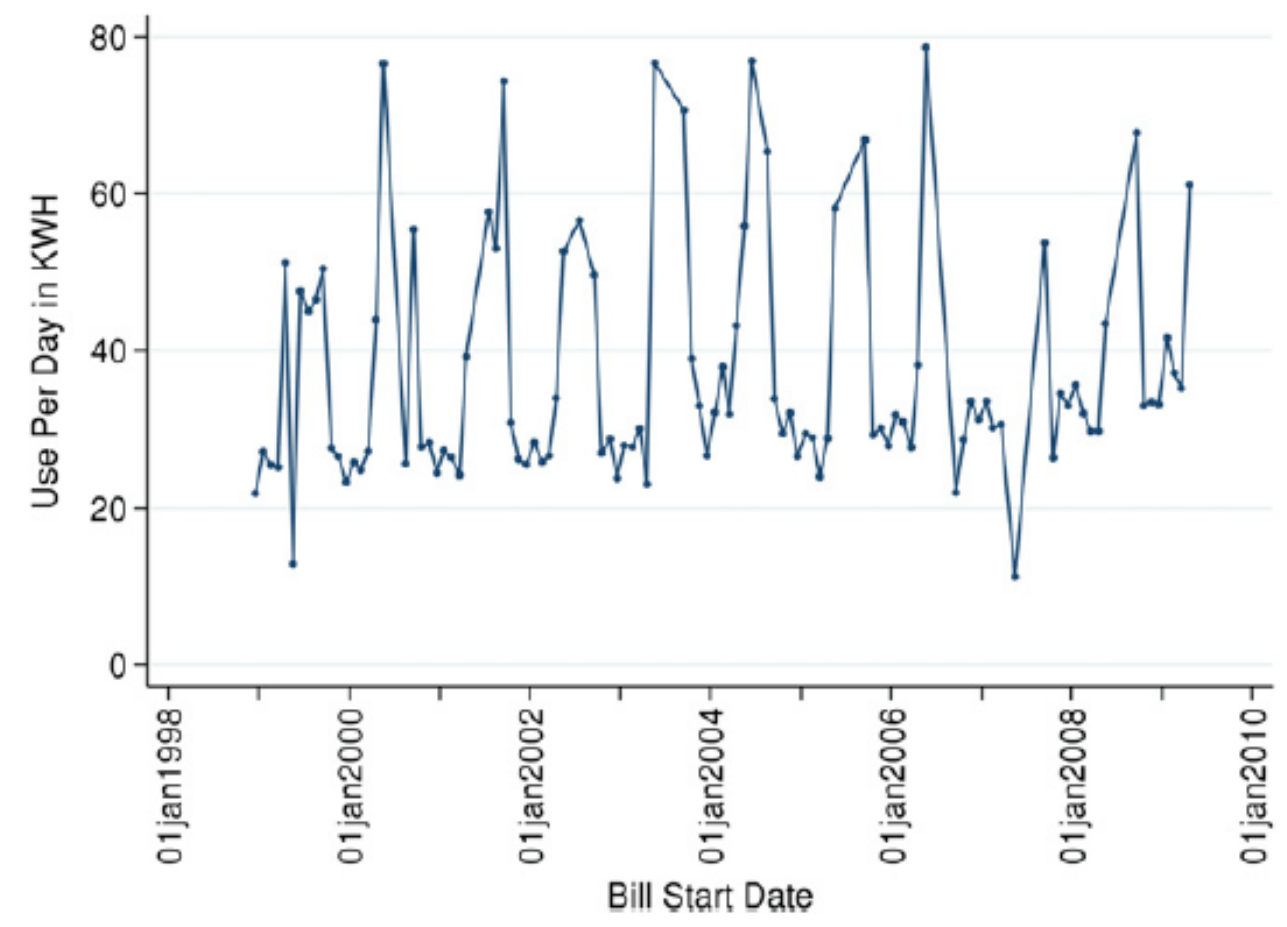

Figure 4 Electricity use (KWH) vs time for one sample household. Source: author's data

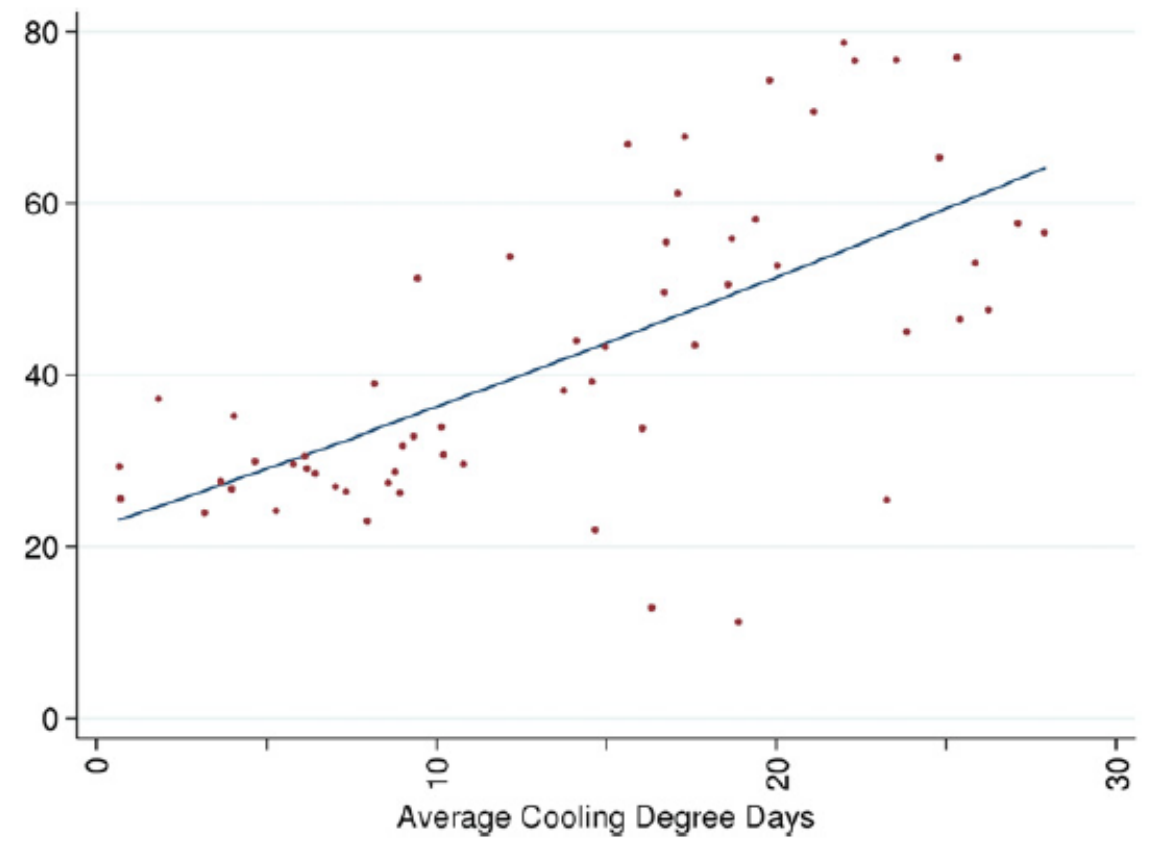

Figure 5 Electricity use (KWH) vs cooling degree days for one sample household. Source: author's data. Note: Days with heating degree days were omitted 
Table 2

Summary statistics.

\begin{tabular}{|c|c|c|c|c|}
\hline Variable & Mean & Std. Dev. & Min & Max \\
\hline \multicolumn{5}{|l|}{ Billing data } \\
\hline Use per day (in kWh) & 24.73 & 14.20 & 2.03 & 79.97 \\
\hline Days & 30.43 & 1.50 & 26 & 34 \\
\hline \multicolumn{5}{|l|}{ Assessor's data } \\
\hline \multicolumn{5}{|l|}{ Building age } \\
\hline Proportion built prior to 1970 & 0.15 & 0.36 & 0 & 1 \\
\hline Proportion built in 1970 s & 0.16 & 0.36 & 0 & 1 \\
\hline Proportion built in 1980 s & 0.54 & 0.50 & 0 & 1 \\
\hline Proportion built in $1990 \mathrm{~s}$ & 0.15 & 0.36 & 0 & 1 \\
\hline \multicolumn{5}{|l|}{ Other characteristics } \\
\hline Square feet & 1750 & 480 & 360 & 7138 \\
\hline Has central air conditioning? & 0.88 & 0.28 & 0 & 1 \\
\hline For pre1970s & 0.407 & & & \\
\hline For 1970 s & 0.847 & & & \\
\hline For $1980 \mathrm{~s}$ & 0.986 & & & \\
\hline For $1990 \mathrm{~s}$ & 0.995 & & & \\
\hline Observations (no subsampling) & $5,625,517$ & & & \\
\hline
\end{tabular}

Table 3

Summary statistics.

\begin{tabular}{|c|c|c|c|c|}
\hline Variable & Mean & Std. Dev. & Min & Max \\
\hline \multicolumn{5}{|l|}{ Billing data } \\
\hline Use per day & 21.61 & 14.56 & 2.03 & 79.97 \\
\hline Days & 30.43 & 1.52 & 26 & 34 \\
\hline \multicolumn{5}{|l|}{ Census data } \\
\hline \multicolumn{5}{|l|}{ Building age } \\
\hline Proportion built prior to 1970 & 0.23 & 0.24 & 0 & 1 \\
\hline Proportion built in 1970 s & 0.20 & 0.16 & 0 & 1 \\
\hline Proportion built in $1980 \mathrm{~s}$ & 0.36 & 0.22 & 0 & 0.94 \\
\hline Proportion built in 1990 s & 0.21 & 0.21 & 0 & 0.98 \\
\hline \multicolumn{5}{|l|}{ Type of structure } \\
\hline Proportion SingleFamily & 0.64 & 0.30 & 0 & 1 \\
\hline Proportion MultiFamily & 0.28 & 0.28 & 0 & 1.00 \\
\hline Proportion MotorOther & 0.073 & 0.15 & 0 & 0.84 \\
\hline \multicolumn{5}{|l|}{ Other characteristics } \\
\hline Average bedrooms & 2.57 & 0.62 & 0.89 & 4.36 \\
\hline Average rooms & 5.23 & 1.01 & 2.31 & 8.00 \\
\hline Average income & $\$ 48,200$ & $\$ 16,600$ & $\$ 13,000$ & $\$ 108,900$ \\
\hline Observations ( 1 -in-5 subsample) & $5,303,019$ & & & \\
\hline
\end{tabular}

To give a better sense of the data, Fig. 4 gives plots of average daily electricity use versus time

from the monthly billing data for one household. Peaks for electricity use correspond to summer months. This data is then replotted as average daily electricity use versus average cooling degree days in Fig. 5. As temperature increases, the electricity use for this household increases.

Summary statistics of the data (using assessor's data which is restricted to single family homes at the ZIP9 level) are in Table 2. Most homes (88\%) have central air conditioning; the newest homes almost always have central air conditioning, but less than half of older homes have central air conditioning. 
Summary statistics of the data (using census block groups) are in Table 3. The top section reports information from the billing data. The average household use per day is $21.61 \mathrm{kWh}$, or $7887 \mathrm{kWh}$ per year. This is lower than the national average of 11,500 kWh per year (Energy Information Administration, 2009), but is consistent with California. The second section of the summary statistics corresponds to building and household characteristics from the Census data at the level of the census block group. $20 \%$ of observations were built in $1970-1979,36 \%$ in $1980-1989$, and $21 \%$ in $1990-2000$, and $23 \%$ before and including 1969 . The min and max of these variables are close to zero and one, which means there is substantial variation across census block groups in building vintage. The vintage variables differ from the previous table because this data set includes non-single family homes. The average number of bedrooms and rooms are 2.57 and 5.23, and the average household income is $\$ 48,200$. Air conditioning information is not available from the Census.

An extended data discussion with additional detail on data cleaning and matching is in Appendix D.

\section{Economic Model}

The average temperature response for subareas of California has been estimated by Aroonruengsawat and Auffhammer (2009) and nationally by ?. A similar estimating equation is given by Eq. (1). This flexibly estimates the average temperature response in log terms within the sample area after controlling for a household fixed effect. ${ }^{11}$ Temperature is binned. $D_{\text {pit }}$ is a scalar $[0,1]$ that denotes the fraction of days where a household is exposed to the $p$ th temperature bin:

(1)

$$
\ln \left(k W h \_ \text {useperday } i t\right)=\sum_{p=1}^{B I N S} \rho_{p} * D_{p i t}+\alpha_{i}+\varepsilon_{i t}
$$

An alternative specification is to parameterize the temperature response in terms of cooling degree days and heating degree days. ${ }^{12}$ Following Reiss and White (2008), I include linear and squared terms for CDD and HDD which results in the following equation:

$$
\ln \left(k W h_{-} \text {seperday }_{i t}\right)=f\left(C D D_{i t}, H D D_{i t}\right)+\alpha_{i}+\varepsilon_{i t}=\beta_{1} C D D_{i t}+\beta_{2} C D D_{i t}^{2}+\beta_{3} H D D_{i t}+\beta_{4} H D D_{i t}^{2}+\alpha_{i}+\varepsilon_{i t}
$$

\footnotetext{
${ }^{11}$ Studies relating energy use and temperature have varied in the functional forms used. I discuss this in Appendix B. In the robustness checks and the auxiliary regressions, I include alternative functional forms.

${ }^{12}$ Degree days are referenced to $65^{\circ} \mathrm{F}$. For a given day, $\mathrm{CDD}=\max (\mathrm{Tmean}-65,0)$ and $\mathrm{HDD}=\max (65-\mathrm{Tmean}, 0)$.
} 
I have estimated both temperature parameterizations. The degree day parameterization is the main specification presented. A limited number of binned results are also presented.

I next estimate the heterogeneity of temperature response by vintage. The vintage of each household is not known, but the proportion of buildings of each vintage in an area is known, either at the ZIP9- or census block group-level. The temperature response of each vintage is estimated via the cross-sectional variation in vintage across areas. Eq. (3) uses the degree day parameterization, while Eq. (4) estimates the average response by vintage using binning:

(3)

$$
\ln \left(k W h \_ \text {useperday } y_{i j t}\right)=\sum_{v=1}^{\text {VINTAGES }} V_{j v} *\left(\beta_{1 v} C D D_{i t}+\beta_{2 v} C D D_{i t}^{2}+\beta_{3 v} H D D_{i t}+\beta_{4 v} H D D_{i t}^{2}\right)+\alpha_{i}+\varepsilon_{i t}
$$

$$
\ln \left(k W h \_ \text {useperday } i j t\right)=\sum_{v=1}^{\text {VINTAGES }}\left(\sum_{p=1}^{\text {BINS }}\left[\beta_{p v} V_{j v}\right]\right) * D_{p i t}+\alpha_{i}+\varepsilon_{i t}
$$

where

- $i, j, t$ index households, ZIP9 or census block groups, and time (monthly billing period), respectively;

- BINS represents the number of temperature bins, $p$ indexes them.

- $\quad$ IINTAGES represents the number of building vintage categories. $v$ indexes them;

- $\mathrm{V}_{\mathrm{jv}}$ is in $[0,1]$ and represents the proportion of buildings in $\mathrm{j}$ for vintage $\mathrm{v}$;

- $D_{p i t}$ is in $[0,1]$ and is the measure of the proportion of days for household $i$ in the billing cycle $t$ where the average temperature is in the pth bin.

In both regressions, the mean temperature-invariant consumption is captured by the household fixed effect, $\alpha_{i}$. Importantly, this will flexibly capture temperature invariant factors such as variation in appliance ownership and usage patterns. ${ }^{13}$ In Eq. (4), the parameters of interest are the $\beta_{p v}$ that represent the temperature response for the $p$ th temperature bin for the $v$ th vintage. ${ }^{14}$ The set of $\beta_{p v}$ plotted against the $p$ temperature bins yields the temperature response. For a given $v$, electricity use

\footnotetext{
${ }^{13}$ A more common specification would also include time dummies. This specification has been run with both month(January-December) and year dummies. The pattern of results is the same for the CDD and HDD parameterization.

${ }^{14}$ One of the temperature bins, $62.7^{\circ} \mathrm{F}-66.4^{\circ} \mathrm{F}$ is left out wlog as the reference temperature bin, otherwise the rank condition is violated.
} 
should increase with increasing temperature, represented by $\beta_{p^{*} v}>\beta_{p^{\prime} v}$ when $p^{*}$ is hotter than $p^{\prime}$ for temperatures above $65^{\circ} \mathrm{F} .{ }^{15}$ If new buildings have higher temperature response than older buildings, then $\beta_{p v^{*}}>\beta_{p v^{\prime}}$ when $v^{*}$ is newer than $v^{\prime}$ for any $p$ for temperatures above $65^{\circ} \mathrm{F}$. In Eq. (3) with the degree day parametrization, the $\beta_{1 v}$ and $\beta_{2 v}$ determine the temperature response to hotter temperatures. Temperature response is higher when these coefficients are larger. In the degree day parameterization, the comparison of interest is the analogous differences in predicted temperature response across vintages.

Estimation of Eqs. (3) and (4) determines the average temperature response by vintage but does not identify the causal effect of building standards. Over time, buildings have changed in numerous ways, such as building standards on insulation and glazing, efficiency standards on appliances, the likelihood to have air conditioning, the square footage, and building design. The standard practice of using $\ln \left(k W h \_\right.$useperday) as the dependent variable is one way to controls for square footage and size as discussed in Appendix B. Other factors are captured by the vintage effect. One of these factors, building standards, do vary by vintage and are predicted via engineering estimates to have an impact on temperature response. However, building standards cannot be isolated from the other changes. ${ }^{16}$ Hence, I interpret the estimate to Eqs. (3) and (4) as the cumulative impact of multiple changes.

In order to aid interpretation of the cumulative effect, available covariates can be added which can isolate some factors of the cumulative impact of vintage, but the remaining factors cannot be isolated. County assessor's data provide additional covariates for central air conditioning ownership and square footage at the ZIP9-level for areas almost entirely composed of single family homes. Using this data, the following auxiliary specifications can be estimated, the first with the degree day parameterization and the second with temperature bins. Importantly, building standards are not controlled for and would still be part of the vintage effect:

\footnotetext{
${ }^{15}$ The heating range of temperatures is estimated but not discussed in this paper. Heating fuel varies across vintage, with newer homes more likely to have natural gas as their primary heating fuel. In contrast, electricity is almost universally the energy source for cooling.

${ }^{16}$ There are two potential methods of estimating the causal impact of building standards. First, a regression discontinuity (RD) design may be possible if the treatment is discontinuous. However, building standards implementation could be slow and gradual, which would not be picked up by an RD design. Jacobsen and Kotchen (2010) apply an RD approach which assumes a sharp change in standards implementation. Second, cross-state comparisons can be made, but the limitations of cross-state analyses has been discussed.
} 
(5)

$$
\begin{aligned}
& \ln \left(k W \text { L }_{-} \text {seperday }_{i z t}\right)=\sum_{v=1}^{\text {VINTAGES }} V_{z v} *\left(\beta_{1 v} C D D_{i t}+\beta_{2 v} C D D_{i t}^{2}+\beta_{3 v} H D D_{i t}+\beta_{4 v} H D D_{i t}^{2}\right) \\
& \quad+\text { CentralAC }_{z} *\left(\varphi_{1} C D D_{i t}+\varphi_{2} C D D_{i t}^{2}+\varphi_{3} H D D_{i t}+\varphi_{4} H D D_{i t}^{2}\right) \\
& \quad+\text { SquareFootage }_{z} *\left(\theta_{1} C D D_{i t}+\theta_{2} C D D_{i t}^{2}+\theta_{3} H D D_{i t}+\theta_{4} H D D_{i t}^{2}\right)+\alpha_{i}+\varepsilon_{i t}
\end{aligned}
$$

(6)

$$
\ln \left(k W h_{-} \text {useperday } i z t\right)=\sum_{p=1}^{\text {BINS }}\left(\sum_{v=1}^{\text {VINTAGES }}\left[\beta_{p v} V_{z v}\right]+\varphi_{p} \text { CentralAC } z+\theta_{p} \text { SquareFootage }_{z}\right) * D_{p i t}+\alpha_{i}+\varepsilon_{i t}
$$

where

- $\quad i, z, t$ index households, ZIP9, and time (monthly billing period), respectively,

- $V_{z v}$ is in $[0,1]$ and represents the proportion of buildings in $z$ for vintage $v$,

- CentralAC $C_{z}$ is the proportion of buildings with central air conditioning in $z$, and

- SquareFootage $e_{z}$ is the median square footage for buildings in $z$.

With the census data, three variables are interacted with temperature response that vary at the census block group-level: (1) average In(income), (2) average number of bedrooms (a proxy for size), and (3) the type of structure, i.e., Single Family or Multifamily or Mobile/Other. Eq. (7) presents this auxiliary specification with the degree day parameterization.

(7)

$$
\begin{aligned}
& \ln \left(k W h_{-}\right. \text {useperday } \\
&i j t)= \sum_{v=1}^{\text {VINTAGES }} V_{j v} *\left(\beta_{1 v} C D D_{i t}+\beta_{2 v} C D D_{i t}^{2}+\beta_{3 v} H D D_{i t}+\beta_{4 v} H D D_{i t}^{2}\right) \\
& \times \sum_{s=1}^{\text {STRUCTURES }} S_{\text {TR }} *\left(\rho_{1 s} C D D_{i t}+\rho_{2 s} C D D_{i t}^{2}+\rho_{3 s} H D D_{i t}+\rho_{4 s} H D D_{i t}^{2}\right) \\
&+ \text { AvinIncome } *\left(\gamma_{1} C D D_{i t}+\gamma_{2} C D D_{i t}^{2}+\gamma_{3} H D D_{i t}+\gamma_{4} H D D_{i t}^{2}\right) \\
&+ \text { AvBedrooms } *\left(\delta_{1} C D D_{i t}+\delta_{2} C D D_{i t}^{2}+\delta_{3} H D D_{i t}+\delta_{4} H D D_{i t}^{2}\right)+\alpha_{i}+\varepsilon_{i t}
\end{aligned}
$$

$\mathrm{STR}_{\mathrm{js}}$ is in $[0,1]$ and represents the proportion of buildings in $\mathrm{j}$ for the type of structure, $s$. AvInIncome $e_{j}$ is the average of In(income) per household in $j$. AvBedrooms $j$ is the average bedrooms per household in j. $\mathrm{j}$ indexes census block groups areas. Importantly, building standards and measures of air conditioning ownership are not available as covariates when using census data. 
An important property of these estimates of temperature response is that they are immune to many types of omitted variable bias. In order for omitted variable bias to bias temperature response results, two conditions must be met. First, the omitted variable must vary across vintage. Second, the omitted variable must be correlated with temperature. A variable, such as price, that does not vary within this region nor by temperature, would not bias results, except if price elasticities for cooling varied across vintages. ${ }^{17}$ Aroonruengsawat and Auffhammer (2009) included price as a regressor in estimating regional temperature response and found that it did not affect results.

\section{Results}

Main Results: Degree Day Parameterization with County Assessor's Data

Results presented in this subsection use the degree day parameterization and county assessor's data. Alternative specifications follow this subsection.

I first estimate the average temperature response across all households given earlier by Eq. (2). Column A1 of Table 4 and Fig. 6 present the results of the estimation using fixed effects panel regression with standard errors clustered at the ZIP9 level. This shows the strong increase in electricity in response to temperature for higher temperatures, relative to $65^{\circ} \mathrm{F} .{ }^{18}$

Next, I estimate temperature response by vintage as given earlier by Eq. (3). Column A2 of Table 4 and Figs. 7-10 present the results of the estimation. The omitted vintage variable is pre1970s, so the coefficients on the remaining variables are different from the temperature response of pre1970s buildings. Fig. 7 is the temperature response for pre1970s buildings. Figs. 8-10 are for each other vintage relative to pre1970s buildings. Each figure has a horizontal line at zero to indicate what would result if there were no difference between vintages. To interpret these results, the 1970s, 1980s, and 1990s vintage of buildings have statistically significantly higher temperature response than pre1970s buildings. The highest temperature response is for 1990s buildings, followed by 1980s buildings, 1970s buildings, and then pre1970s buildings.

\footnotetext{
${ }^{17}$ This is a future piece of planned work. It is not straightforward to include prices because they are nonlinear, increasing block rate tariffs, which makes prices endogenous.

${ }^{18}$ The heating curves or temperatures below $65^{\circ} \mathrm{F}$ are not included because electricity is not the dominant heating fuel. Hence estimated differences across vintages will be partly driven by differences in heating fuel. Reliable statistics of heating fuel across area are not available. Natural gas is more common in newer buildings and in some areas. Heating is still included to improve model fit and reduce standard errors.
} 
Table 4

Estimation results, temperature response with CDD and HDD parameterization, assessor's data. Dependent variable is In(KWH_perday).

\begin{tabular}{|c|c|c|c|c|}
\hline Variables & (A1) & (A2) & (A3) & (A4) \\
\hline \multirow[t]{2}{*}{ CDD } & $0.0553^{*}$ & $0.0460^{\circ}$ & $0.0355^{2}$ & $0.0476^{+* * *}$ \\
\hline & {$[0.000330]$} & {$[0.000930]$} & [0.00149] & {$[0.00321]$} \\
\hline \multirow[t]{2}{*}{ HDD } & $0.0274^{m+0}$ & $0.0293^{+00}$ & 0.0231 & $0.0326^{+0 * *}$ \\
\hline & {$[0.000268]$} & [0.000905] & [0.00132] & [0.00286] \\
\hline \multirow[t]{2}{*}{$C D D^{2}$} & $-0.000283^{2}$ & $-0.000185^{*+\infty}$ & 0.000234 & $-0.000270^{*}$ \\
\hline & [1.61e-05] & {$[4.44 e-05]$} & {$[8.27 e-05]$} & {$[0.000164]$} \\
\hline \multirow[t]{2}{*}{$H D D^{2}$} & $-0.000590^{\circ}$ & $-0.000743^{* * *}$ & $-0.000260^{\circ+6}$ & $-0.000802^{2}$ \\
\hline & [1.87e-05] & {$[6.64 e-05]$} & [8.93e-05] & [0.000191] \\
\hline \multirow[t]{2}{*}{ Built in $1990 \times \mathrm{CDD}$} & & $0.0149^{\ldots}$ & 0.0108 & $0.00871^{\circ}$ \\
\hline & & {$[0.00121]$} & {$[0.00160]$} & {$[0.00300]$} \\
\hline \multirow[t]{2}{*}{ Built in $1980 \times \mathrm{CDD}$} & & $0.0117^{+\infty}$ & $0.00482^{+\infty}$ & $0.00827^{\text {tot }}$ \\
\hline & & {$[0.00103]$} & {$[0.00141]$} & {$[0.00246]$} \\
\hline \multirow[t]{2}{*}{ Built in $1970 \times \mathrm{CDD}$} & & $0.00393^{\circ}$ & 0.000171 & 0.000292 \\
\hline & & {$[0.00201]$} & {$[0.00210]$} & {$[0.00371]$} \\
\hline \multirow[t]{2}{*}{ Built in $1990 \times$ HDD } & & -0.00049 & $-0.00306^{+\infty}$ & -0.00364 \\
\hline & & {$[0.00109]$} & [0.00139] & {$[0.00248]$} \\
\hline \multirow[t]{2}{*}{ Built in $1980 \times \mathrm{HDD}$} & & $-0.00195^{\star}$ & $-0.00502^{2}$ & $-0.00359^{*}$ \\
\hline & & {$[0.000976]$} & {$[0.00125]$} & {$[0.00208]$} \\
\hline \multirow{2}{*}{ Built in $1970 \times \mathrm{HDD}$} & & $-0.00800^{\circ+2}$ & $-0.00980^{+}$ & $-0.00984^{-60}$ \\
\hline & & {$[0.00161]$} & {$[0.00169]$} & {$[0.00295]$} \\
\hline \multirow[t]{2}{*}{ Built in $1990 \times C D D^{2}$} & & $-0.000242^{* * t}$ & $-0.000151^{* *}$ & $-3.00 E-05$ \\
\hline & & {$[5.61 \mathrm{e}-05]$} & {$[6.81 \mathrm{e}-05]$} & {$[0.000116]$} \\
\hline \multirow[t]{2}{*}{ Built in $1980 \times C D D^{2}$} & & $-0.000130^{*+*}$ & $7.86 \mathrm{E}-05$ & $-2.47 \mathrm{E}-0.5$ \\
\hline & & {$[5.00 \mathrm{e}-05]$} & {$[5.98 \mathrm{e}-05]$} & {$[9.66 \mathrm{e}-05]$} \\
\hline \multirow[t]{2}{*}{ Built in $1970 \times C D D^{2}$} & & $7.56 \mathrm{E}-05$ & 0.000147 & $0.000384^{*+}$ \\
\hline & & {$[0.000114]$} & [0.000113] & {$[0.000195]$} \\
\hline \multirow[t]{2}{*}{ Built in $1990 \times H D D^{2}$} & & $0.000128^{*}$ & 0.000114 & 0.000201 \\
\hline & & {$[7.71 \mathrm{e}-05]$} & {$[9.32 \mathrm{e}-05]$} & {$[0.000154]$} \\
\hline \multirow{2}{*}{ Built in $1980 \times H D D^{2}$} & & $0.000156^{\circ *}$ & $0.000263^{200}$ & $0.000261^{*}$ \\
\hline & & {$[7.02 \mathrm{e}-05]$} & {$[8.61 \mathrm{e}-05]$} & {$[0.000133]$} \\
\hline \multirow[t]{2}{*}{ Built in $1970 \times H D D^{2}$} & & $0.000674^{*+*}$ & $0.000737^{*}$ & 0.000598 \\
\hline & & {$[0.000106]$} & [0.000109] & {$[0.000186]$} \\
\hline \multirow[t]{2}{*}{ Central air conditioning $\times$ CDD } & & & $0.0160^{\circ}$ & $0.00803^{* *}$ \\
\hline & & & {$[0.00186]$} & {$[0.00318]$} \\
\hline \multirow[t]{2}{*}{ Central air conditioning $\times$ HDD } & & & $0.00822^{+10}$ & 0.000798 \\
\hline & & & {$[0.00164]$} & {$[0.00275]$} \\
\hline \multirow[t]{2}{*}{ Central air conditioning $\times C D D^{2}$} & & & $-0.000554^{-10}$ & $-0.000287^{*}$ \\
\hline & & & {$[8.98 \mathrm{e}-05]$} & {$[0.000151]$} \\
\hline \multirow[t]{2}{*}{ Central air conditioning $\times H D D^{2}$} & & & $-0.000534^{+10}$ & -0.00014 \\
\hline & & & {$[0.000110]$} & {$[0.000181]$} \\
\hline Square feet ${ }^{2} \times$ CDD & & & -0.00516 & $0.00621^{+\infty}$ \\
\hline & & & {$[0.000482]$} & [0.00295] \\
\hline Square feet ${ }^{2} \times$ HDD & & & $-0.00239^{+\infty}$ & $0.00540^{*+\infty}$ \\
\hline & & & {$[0.000360]$} & {$[0.00257]$} \\
\hline Square feet ${ }^{2} \times C D D^{2}$ & & & $0.000241^{\text {tot }}$ & $-0.000235^{*}$ \\
\hline & & & {$[2.66 \mathrm{e}-0.05]$} & {$[0.000134]$} \\
\hline Square feet ${ }^{2} \times H D D^{2}$ & & & $0.000243^{*}$ & $-4.91 \mathrm{E}-05$ \\
\hline & & & {$[2.16 e-05]$} & {$[0.000164]$} \\
\hline Constant & $2.704^{m+n}$ & $2.705^{m+\infty}$ & $2.710^{+\infty+\infty}$ & 2597 \\
\hline & {$[0.00122]$} & {$[0.00138]$} & {$[0.00151]$} & {$[0.00244]$} \\
\hline Observations & $5,625,517$ & $5,625,517$ & $5,625,517$ & $1,652,525$ \\
\hline$R$-squared & 0.363 & 0.366 & 0.367 & 0.414 \\
\hline Number of households & 118,252 & 118,252 & 118,252 & 37,984 \\
\hline
\end{tabular}

Includes household-level fixed effects. represent $10 \%, 5 \%$, and $1 \%$ statistical significance, respectively. Robust standard errors clustered at the ZIP9-level.

The square feet variable has been demeaned ( 1750 sqft) and rescaled by the population standard deviation ( 480 sqft).

Lastly, I estimate temperature response by vintage with some controls interacted with temperature response, as given by Eq. (5). These controls capture variation in temperature response that is correlated with central air conditioning and square footage. Results are in Column A3 of Table 4 and Fig. 11 which combines the graphs. Central air conditioning strongly positively increases temperature response and is more prevalent in newer buildings. Square feet negatively impacts CDD; this means that the percentage increase in electricity on a hot day is systematically less for larger 
buildings. This makes sense from an engineering perspective because a doubling of sqft typically would mean a less-than-doubling of surface area. As discussed in Appendix B, the main econometric specification assumes comparability across households of different size by comparing percent changes. In the figure, all of the temperature response curves shift downward because new buildings more often have air conditioning. The 1970 s buildings are not statistically significantly different from pre1970s buildings after adding controls. The 1980s and 1990s buildings are more temperature responsive after adding controls.

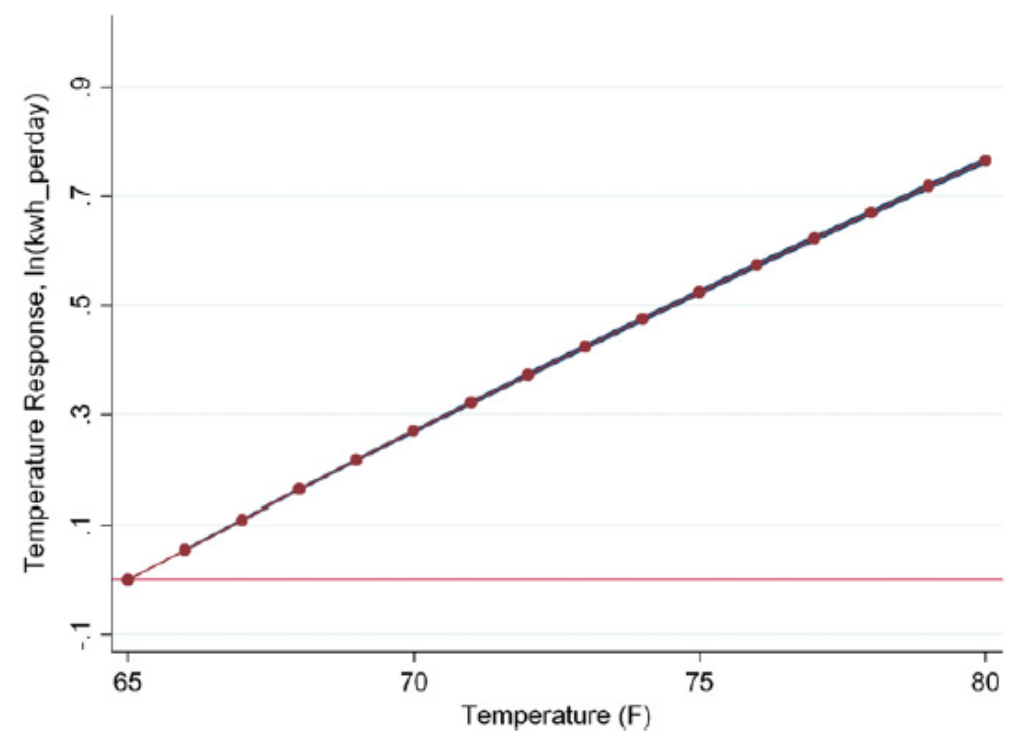

Figure 6 Estimation results, temperature response with CDD and HDD parameterization, assessor's data, average across all vintages Dependent variable is $\ln \left(K W H \_p e r d a y\right)$. The range represents the $95 \%$ confidence interval. 


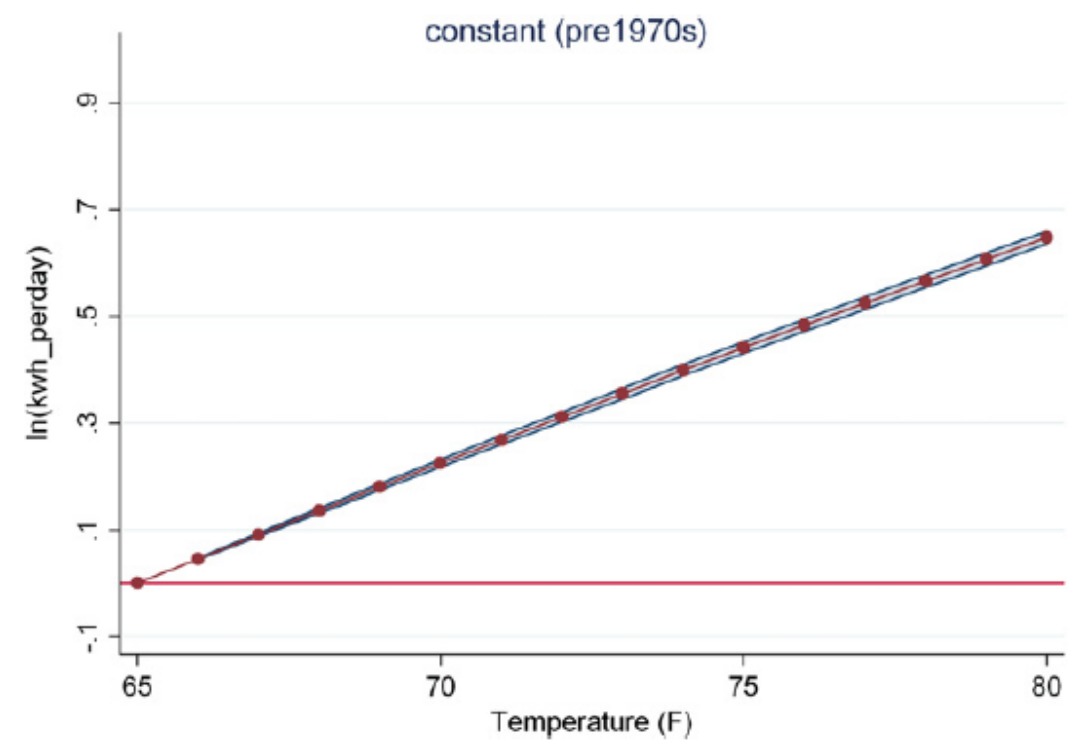

Figure 7 Estimation results, temperature response with CDD and HDD parameterization, assessor's data, by vintage. pre 1970 s reference curve. Dependent variable is $\ln \left(\mathrm{KWH} \_\right.$perday). The range represents the $95 \%$ confidence interval with robust standard errors clustered at the ZIP9-level.

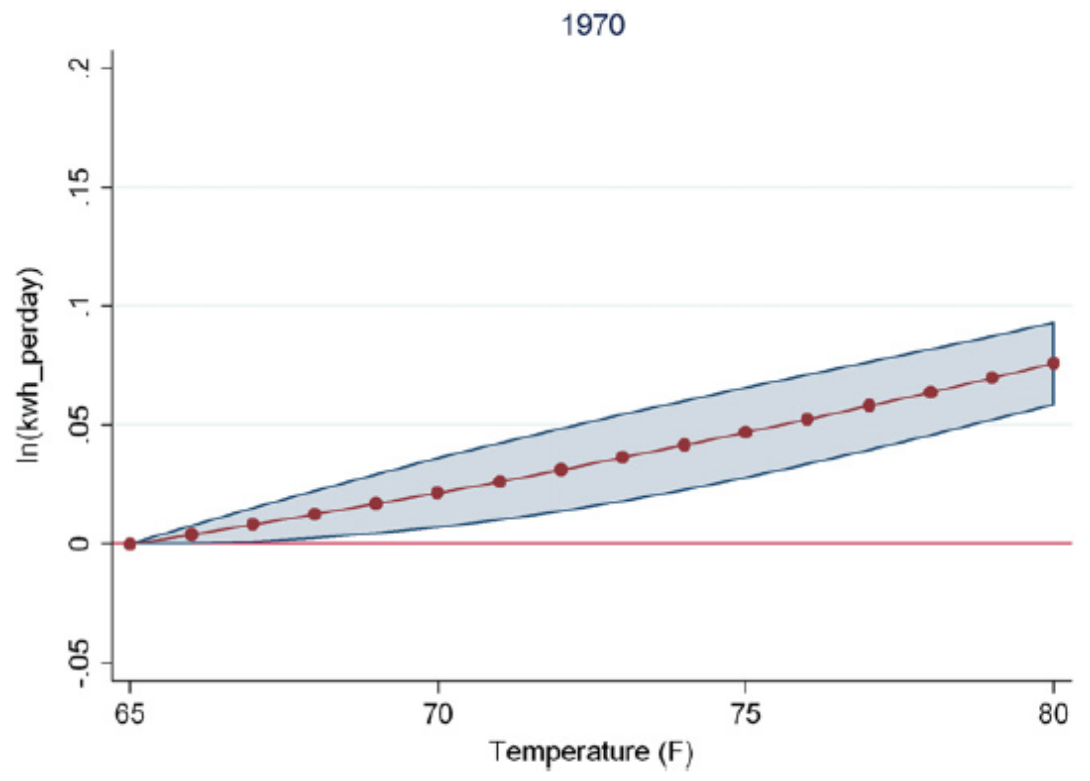

Figure 8 Estimation results, temperature response with CDD and HDD parameterization, assessor's data, by vintage. The 1970 s relative to pre 1970 s curve. Dependent variable is In(KWH_perday). The range represents the $95 \%$ confidence interval with robust standard errors clustered at the ZIP9-level. 


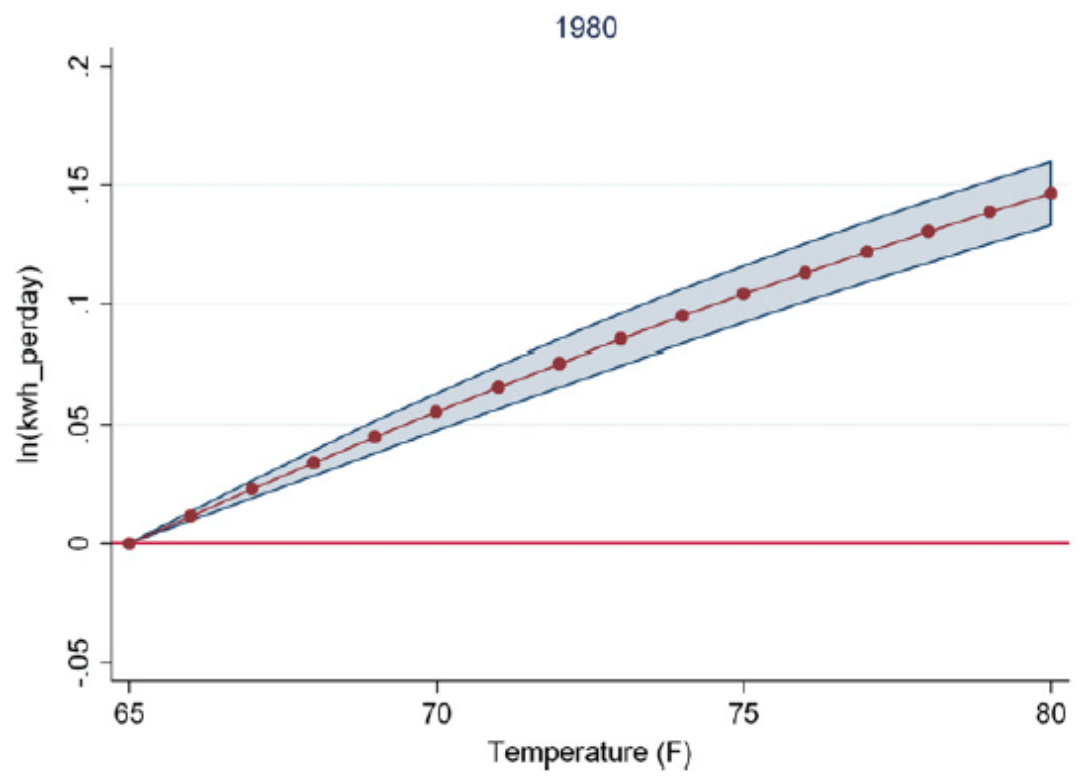

Figure 9 Estimation results, temperature response with CDD and HDD parameterization, assessor's data, by vintage. The 1980 s relative to pre1970s curve. Dependent variable is In(KWH_perday). The range represents the $95 \%$ confidence interval with robust standard errors clustered at the ZIP9-level.

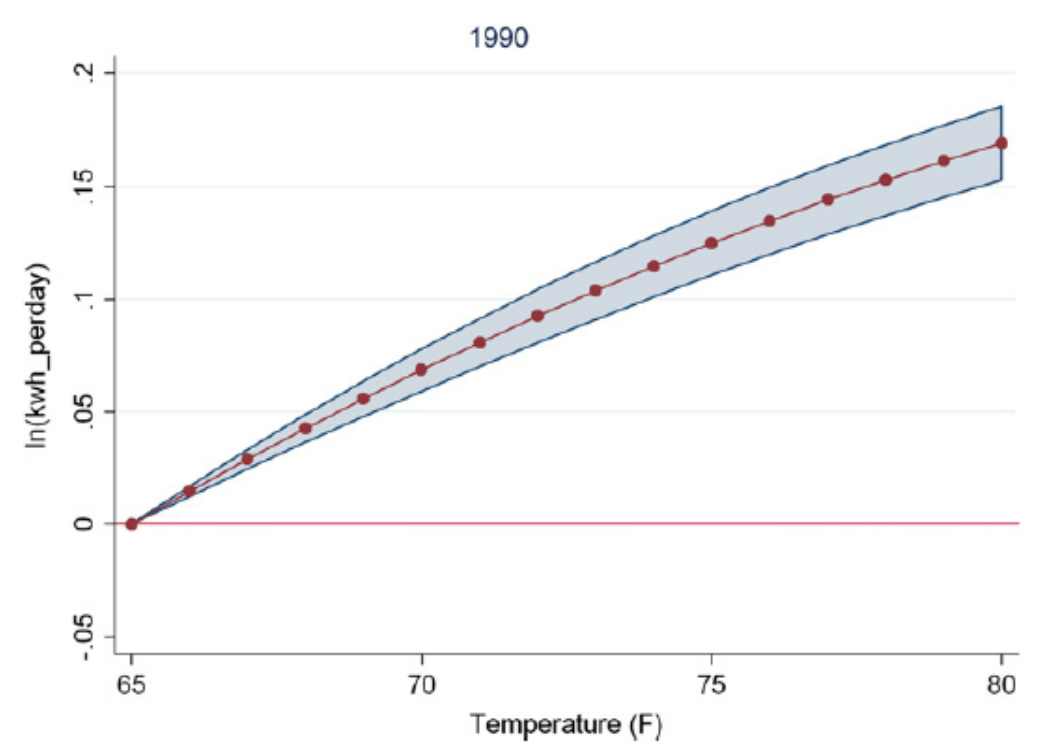

Figure 10 Estimation results, temperature response with CDD and HDD parameterization, assessor's data, by vintage. The 1990 s relative to pre1970s curve. Dependent variable is In(KWH_perday). The range represents the $95 \%$ confidence interval with robust standard errors clustered at the ZIP9-level.

\section{Robustness Checks}

To partially guard against the possibility that some of these results are driven by parametric assumptions on size, I re-estimate the previous regression and restrict square footage from 1300 to 1600 square feet which reduced the observations by about two-thirds. Estimation results are presented 
in Column A4 of Table 4 and Fig. 12. As seen in the figure, the pattern of temperature response by vintage is similar to the main results.

The degree day parameterization may be overly restrictive by setting $651 \mathrm{~F}$ as the reference temperature and by imposing a quadratic form. I run analogous regressions but with temperature binning instead of the degree day parameterization. Eq. (4) presents the regression without controls. Results are given in Fig. 13. Eq. (6) presents the regression with controls. Results are given in Fig. $14 .{ }^{19}$ Results are similar to the main results. Without controls, all vintages have statistically higher temperature response for most bins higher than $65^{\circ} \mathrm{F}$. With controls, 1970s buildings are not statistically significantly different from pre1970s buildings for all bins, and 1980s and 1990s buildings are more temperature responsive. ${ }^{20}$

In each of these cases, the $\ln \left(\mathrm{kWh}_{\text {perday }}\right)$ specification compares households in terms of the percent change in electricity use relative to each house's fixed effect, i.e., their temperature invariant mean usage. An alternative approach is to compare each household's temperature response in levels (as opposed to percentages) and control explicitly for size. This alternative is discussed and estimated in Appendix B. Referring to Fig. 15, this parameterization shows that the predicted temperature response for all vintages of buildings are not statistically significantly different from the reference group of pre1970s buildings. Standard errors are larger due to the reduction in observations.

\footnotetext{
${ }^{19}$ Regression tables available upon request.

${ }^{20}$ Note that caution should be used when looking at the lowest and highest temperature bins. These bins contain outliers and the intra-bin temperature distribution across vintages is quite large. Newer buildings have more data points in the highest temperature bin.
} 

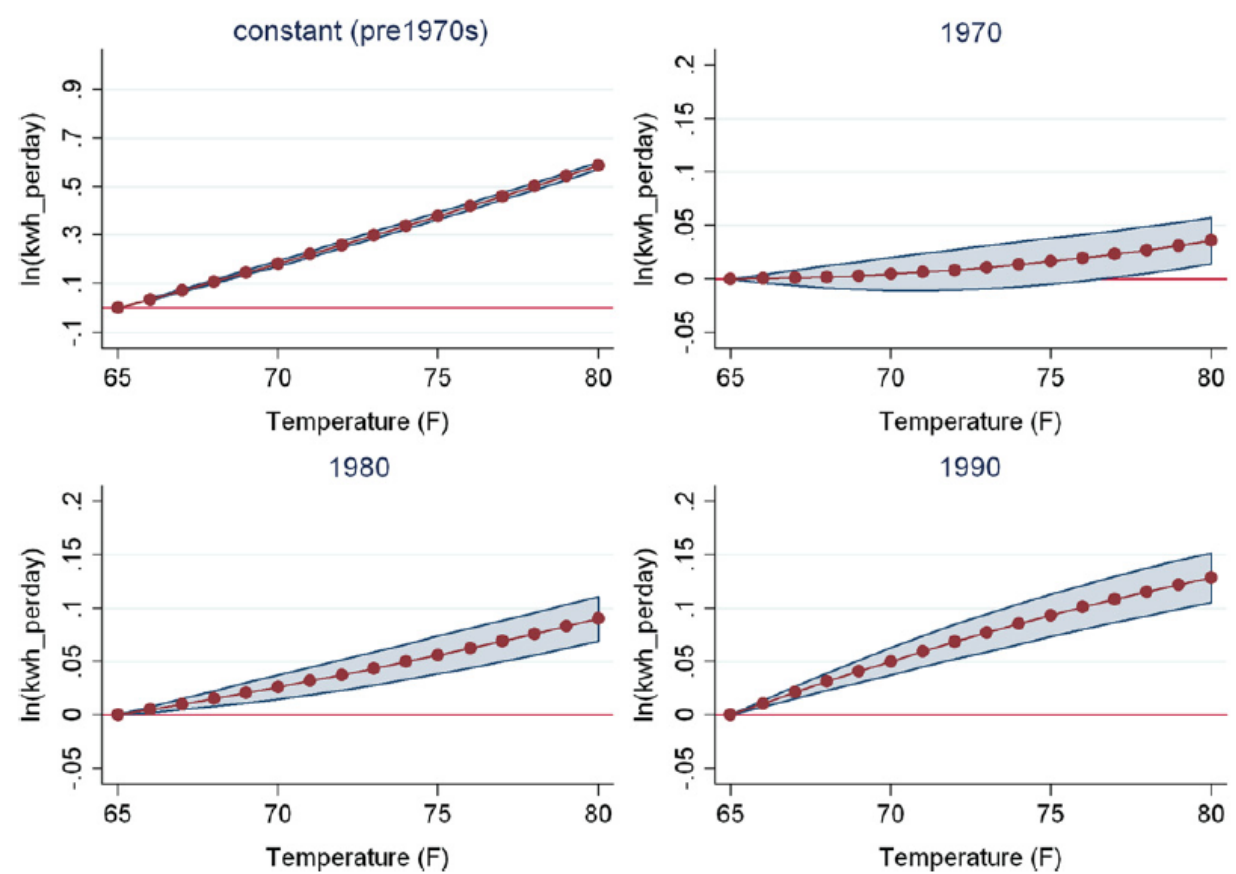

Figure 11 Estimation results, temperature response with CDD and HDD parameterization, assessor's data, by vintage, with controls. Dependent variable is $\ln (\mathrm{KWH}$ _perday). The range represents the $95 \%$ confidence interval with robust standard errors clustered at the ZIP9-level. Top left graph is the reference curve for pre1970s buildings. The remaining curves are the relative temperature responses of the other vintages.
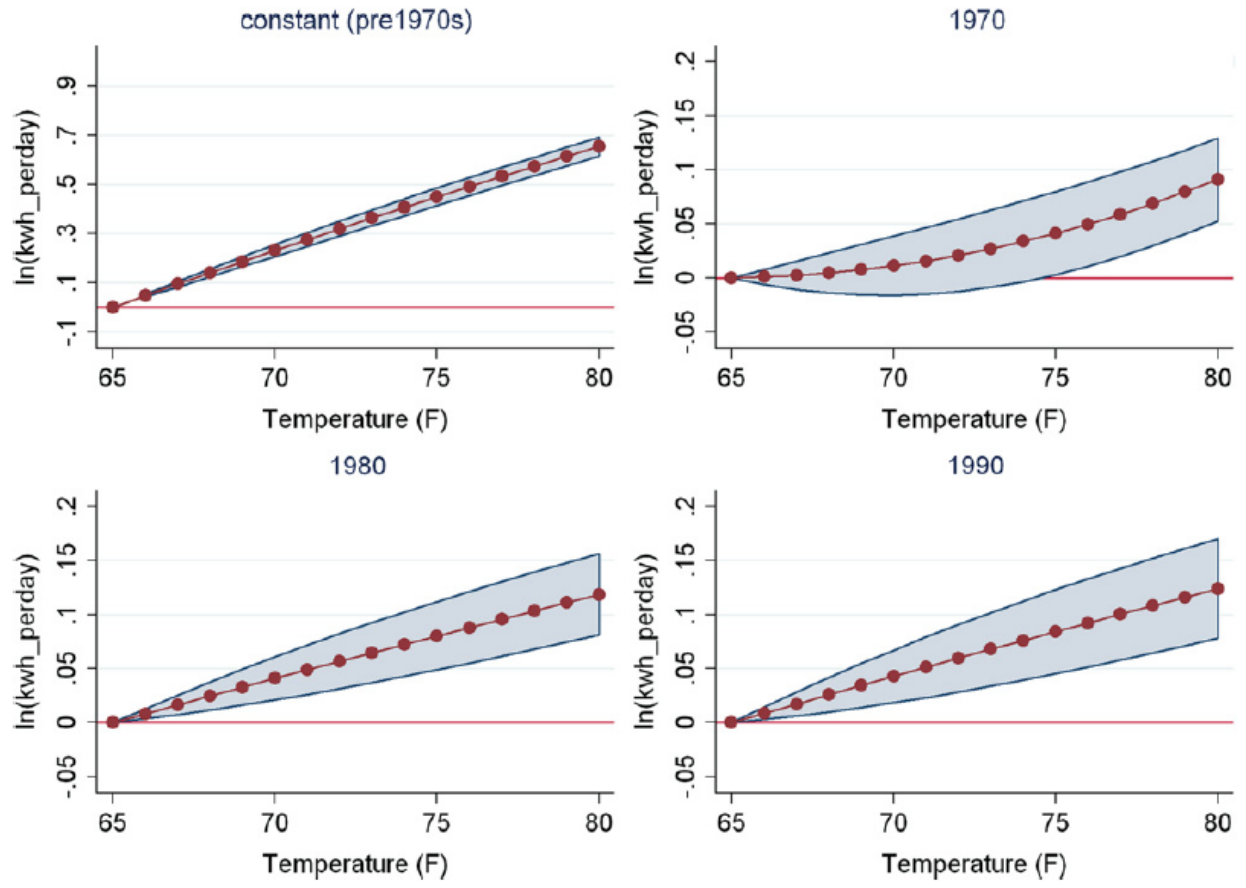

Figure 12 Estimation results, temperature response with CDD and HDD parameterization, assessor's data, by vintage, with controls. Home size restricted to 1300-1600 sqft. Dependent variable is $\ln (\mathrm{KWH}$ _perday). The range represents the $95 \%$ confidence interval with robust standard errors clustered at the ZIP9-level. Top left graph is the reference curve for pre1970s buildings. The remaining curves are the relative temperature responses of the other vintages. 

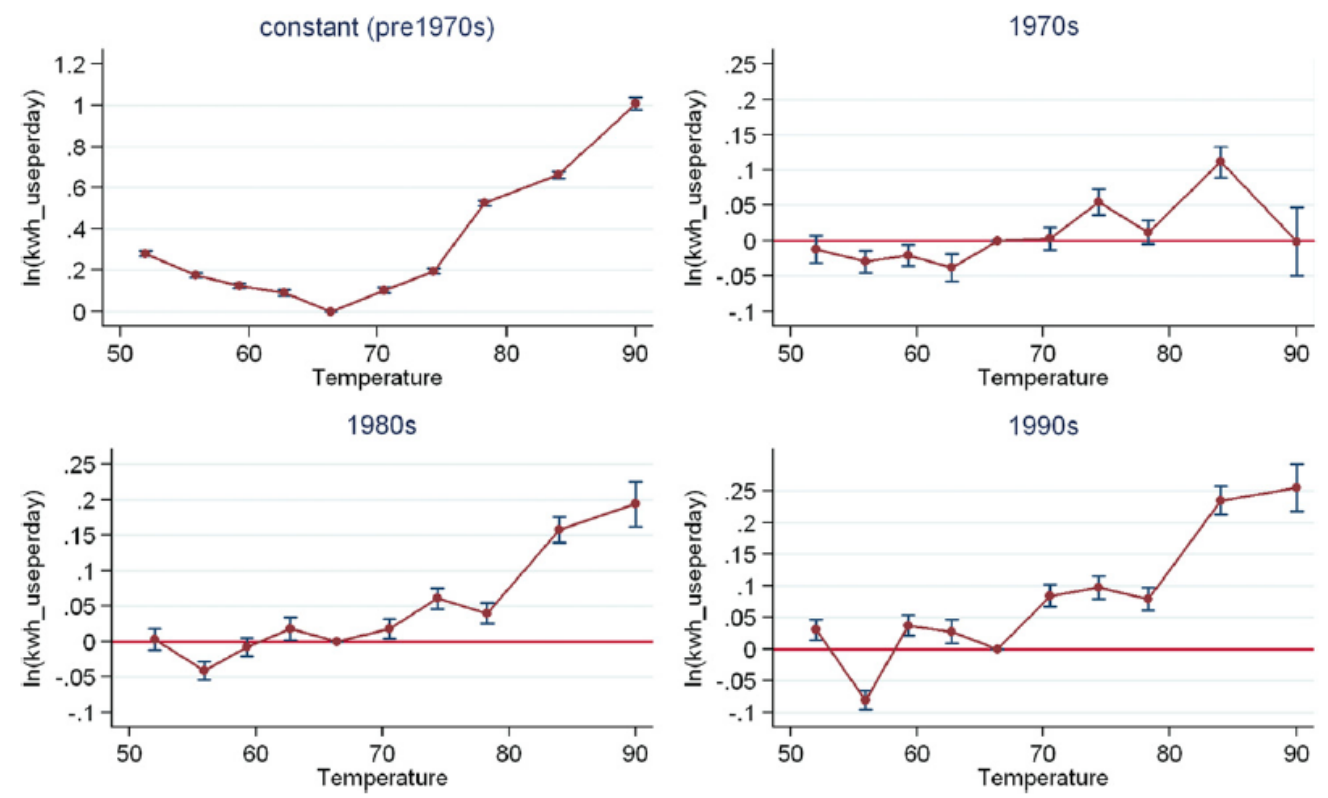

Figure 13 Estimation results, temperature response with binning, assessor's data, by vintage, no controls. Dependent variable is In(KWH_perday). The range represents the $95 \%$ confidence interval with robust standard errors clustered at the ZIP9-level. Top left graph is the reference curve for pre1970s buildings. The remaining curves are the relative temperature responses of the other vintages.

An alternative data source is census data which offers some advantages. Census data is not restricted to single family homes and includes income and other socioeconomic information. The disadvantage is that census block groups are larger geographically, so there is less spatial variation and more potential for bias from aggregation, as discussed in Appendix C. Regressions are run with census block data. Fig. 16 shows the temperature response by vintage after estimating Eq. (3). The 1980s and 1990s homes have a higher temperature response that is not statistically significantly different from pre1970s homes, but 1970s homes have a lower temperature response. Standard errors are much larger due to the decrease in number of areas. There are 372 census block group areas compared to 9316 ZIP9 areas. Fig. 17 shows the results of estimating temperature response by vintage with controls for income, size, and type of structure, as described in Eq. (7). Note that air conditioning is not available at this spatial resolution and is not used as a control. With controls, results change dramatically. The 1970 s buildings have a higher temperature response that is not statistically significant. The 1980s and 1990s buildings have a higher temperature response that is statistically significant. The reason for the upward shift is that 1970s and 1980s buildings had a higher proportion of multifamily and mobile home units which have lower temperature response. After controlling for this, both curves shift upward. For the 1990s buildings, income has a negative effect on temperature response and households in newer building have higher income. After controlling for this, the 1990s curve shifts upward. 
Total usage is another way to compare electricity use across households. This research focuses on temperature response under the rationale that temperature response isolates elements of the building and household preferences only for cooling and heating services. In contrast, total usage captures many other differences across vintages, such as the number and type of appliance. Appendix A discusses this in more depth. The results, as presented in Table 5, show that new homes use statistically significantly more electricity than older homes in total electricity use (Column T1). This is expected since new homes are larger.

After adding controls for square footage and central air conditioning (Column T2) and additionally temperature (Column T3), new houses have statistically significantly less total use, but inferring that new homes are hence more thermally efficient is incorrect. This empirical result can be justified without invoking increased efficiency; a home with twice the square footage may not have twice the amount of people or appliance usage. The lower electricity per sqft is also consistent with fewer services per square foot.

An anonymous referee noted that electricity use varies across household tenure; that is, electricity steadily increases after a household's first bill which often represents a new move-in. If there were systematically more move-ins for certain households, this could bias the results downward. To address this, the main regression was re-run restricted to accounts that were originally opened in 1999 or earlier. ${ }^{21}$ The pattern of higher temperature response for newer buildings remains.

\footnotetext{
${ }^{21}$ Regression results are available upon request.
} 

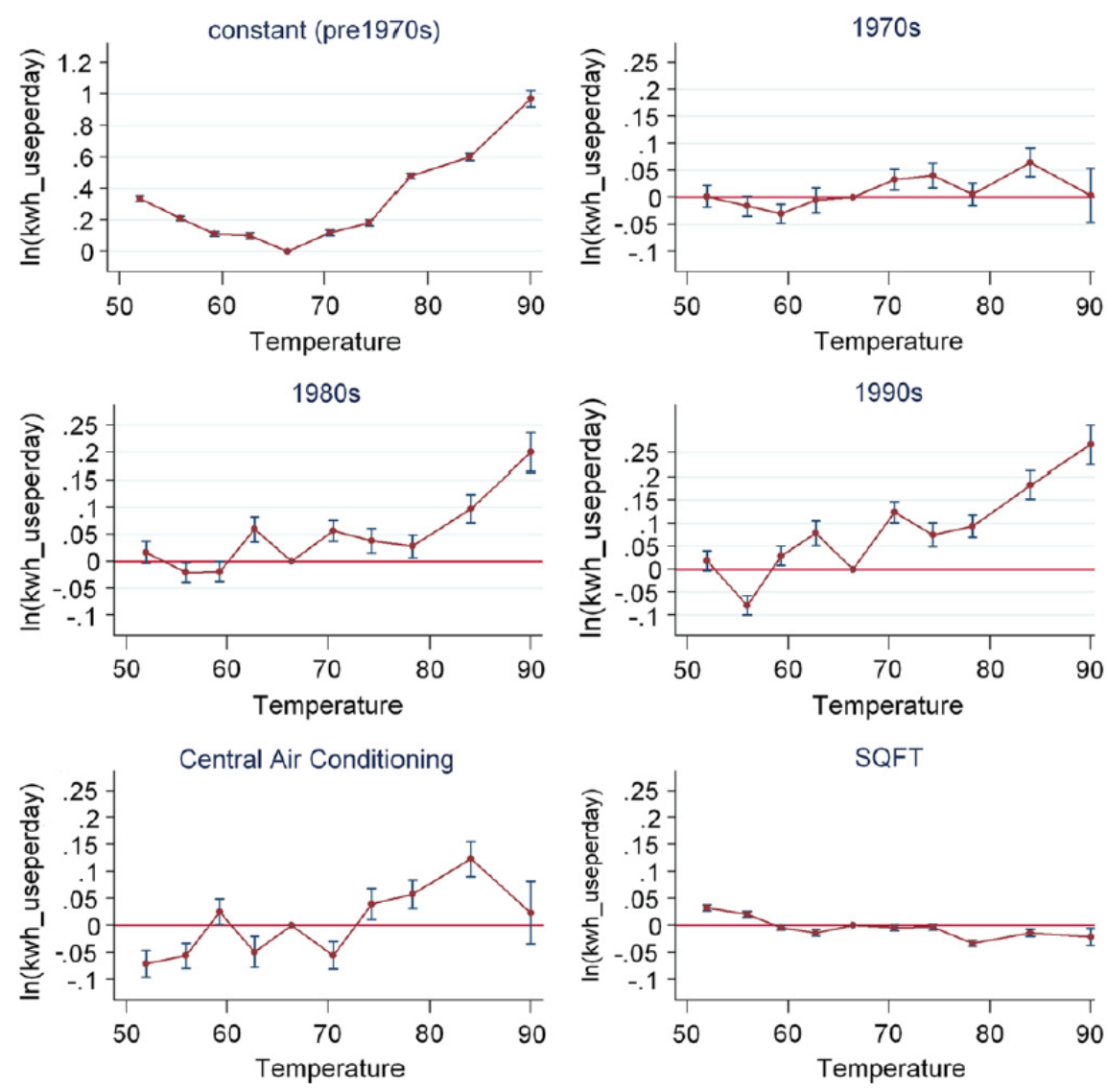

Figure 14 Estimation results, temperature response with binning, assessor's data, by vintage, with controls. Dependent variable is In(KWH_perday). The range represents the $95 \%$ confidence interval with robust standard errors clustered at the ZIP9-level. Top left graph is the reference curve for pre1970s buildings. The next three curves are the relative temperature responses of the other vintages. The bottom curves plot the impact of central air conditioning and square footage.

\section{Robustness to Electricity Price Changes}

The main results are robust to changes in electricity prices which could decrease the quantity demanded. This statement is supported by two approaches: (1) running the same regression restricted to periods of unchanging prices and (2) estimating the main regression but adding an additional control for prices.

In the first approach, three time periods where electricity prices were flat for SCE customers were identified. ${ }^{22}$ The full regression results, available upon request, show that results in these periods without price changes show the same pattern for temperature response across vintage.

In the second approach, price elasticities were estimated. An important note is that customers in SCE territory face a five-tiered increasing block tariff structure. As discussed extensively by Ito (2010), normal OLS regression will be biased because the individual level prices are a direct function of usage.

\footnotetext{
${ }^{22}$ The three periods are $2001 \mathrm{~m} 8$ to $2003 \mathrm{~m} 7,2003 \mathrm{~m} 9$ to $2005 \mathrm{~m} 4$, and $2007 \mathrm{~m} 4$ to $2009 \mathrm{~m} 4$.
} 
Individual level prices need to be instrumented, and a potential instrument is a distant previous period's tier. The instrument is valid if the error in the estimating period is uncorrelated with the usage from a distant previous period. I use 1999 usage/tiers as an instrument and estimate price elasticity and temperature response from data for 2003-2008.

Table 6 reports results of the regressions. The columns correspond to regressions using (I) no prices, (II) instrumented individual marginal prices, (III) instrumented individual average prices, ${ }^{23}$ and (IV) non-instrumented community-wide average prices. ${ }^{24}$ Price elasticities are negative and small, except for the case where community-wide average prices are used without an instrument. In all four cases, the pattern of the coefficients on CDD and SqCDD follow the pattern of the main result: newer homes have a higher temperature response. This is consistent with the observation that bias on the vintage coefficients from omitting prices would require price changes to be correlated with both CDD and vintages. This is confirmed by this regression analysis.

By running these regressions on (1) periods of flat prices as well as (2) regression with price where price is appropriately instrumented or aggregated to the community, I conclude that there is good evidence to suggest that prices are not what is driving the main result. Using periods of flat prices is slightly stronger evidence because it does not depend on the functional form chosen or assumptions about how consumers respond to price changes.

\footnotetext{
${ }^{23}$ Following Ito (2010) which suggests, using a regression discontinuity framework, that customers respond to average, not marginal prices, I include average prices as a specification.

${ }^{24}$ Community-wide average prices represent the average of average prices across consumers in a given year and month. The motivation for this is that it is a simple measure of the general price change. The drawback is that it does not reflect the individual level price.
} 

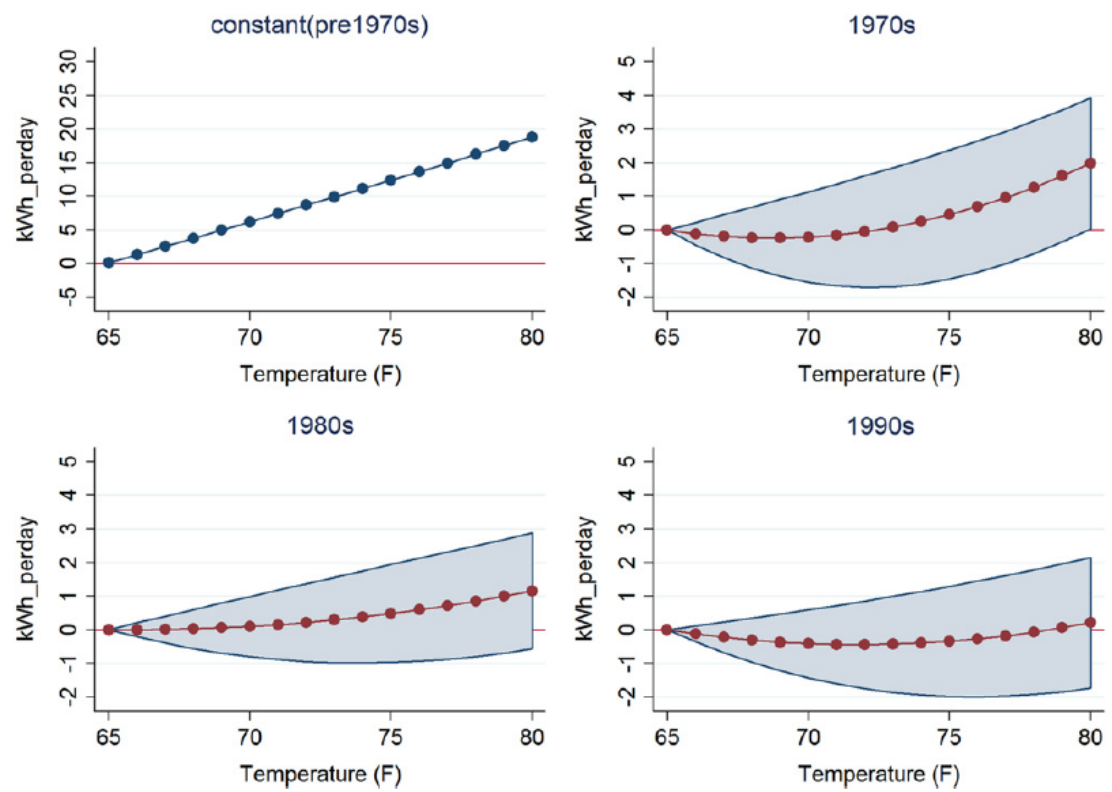

Figure 15 Estimation results, temperature response with CDD and HDD parameterization, assessor's data, by vintage, with controls. Home size restricted to 1300-1600 sqft. Dependent variable is KWH_perday. The range represents the 95\% confidence interval with robust standard errors clustered at the ZIP9-level. Top left graph is the reference curve for pre1970s buildings. The remaining curves are the relative temperature responses of the other vintages.
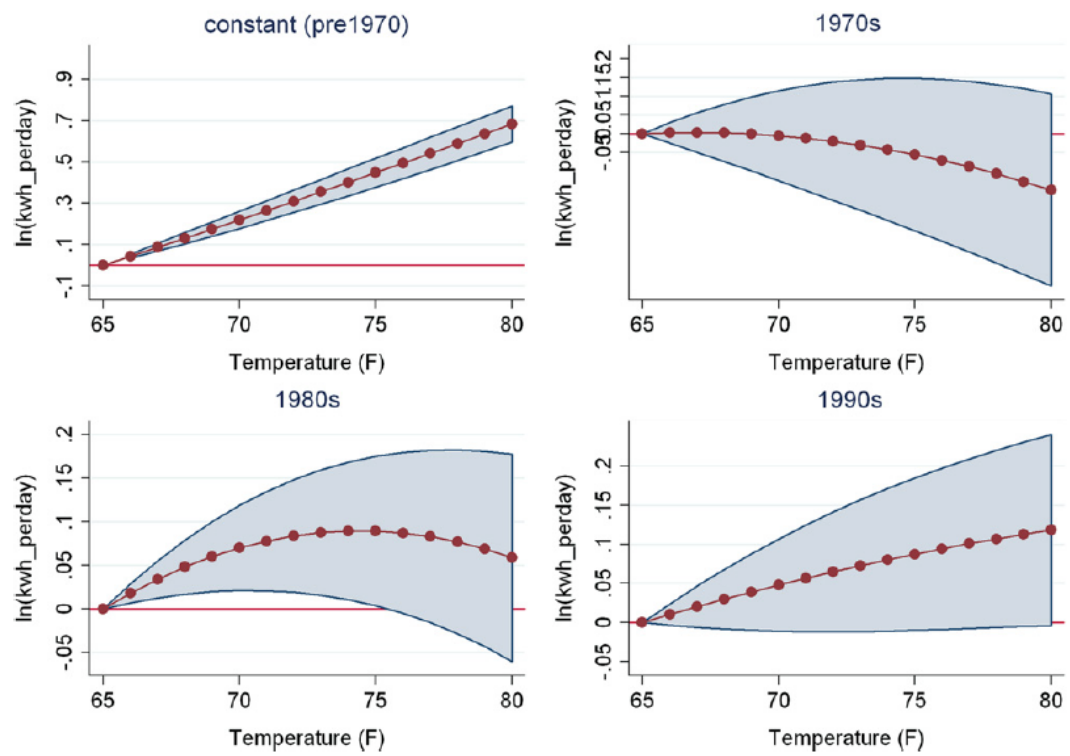

Figure 16 Estimation results, temperature response with CDD and HDD parameterization, census data, by vintage, no controls. Dependent variable is $\ln \left(\mathrm{KWH} \_p e r d a y\right)$. The range represents the $95 \%$ confidence interval with robust standard errors. Top left graph is the reference curve for pre1970s buildings. The next three curves are the relative temperature responses of the other vintages. 

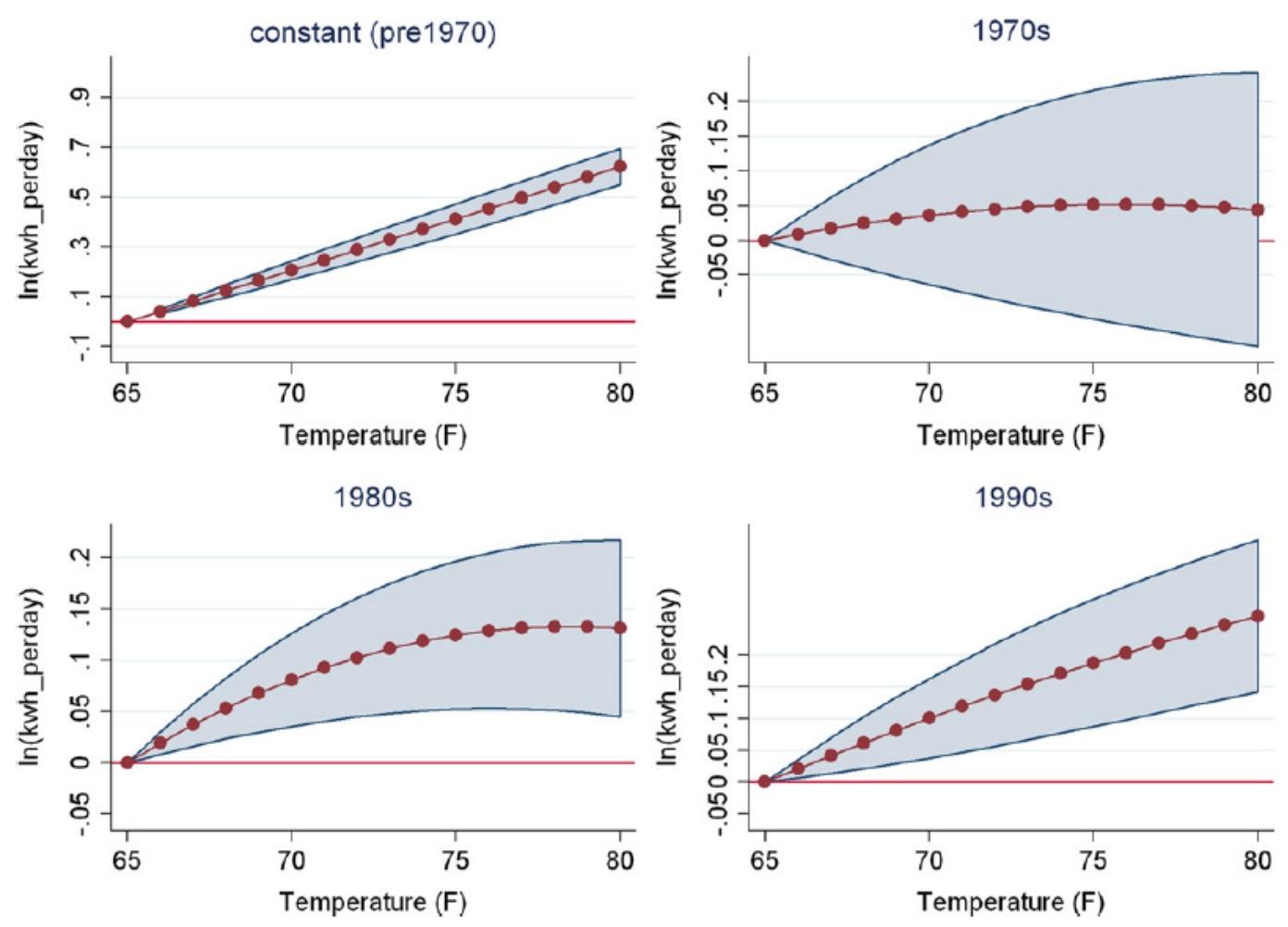

Figure 17 Estimation results, temperature response with CDD and HDD parameterization, census data, by vintage, with controls for type of structure, bedrooms, and income. Dependent variable is $\ln (\mathrm{KWH}$ _perday). The range represents the $95 \%$ confidence interval with robust standard errors. Top left graph is the reference curve for pre1970s buildings. The next three curves are the relative temperature responses of the other vintages. Variation in temperature response by the three controls

(structure, bedrooms, and income) are omitted.

Table 5

Estimation results, Differences across vintage for total usage, assessor's data. Dependent variable is $\ln \left(K_{W} H_{-}\right.$ perday).

\begin{tabular}{llll}
\hline Variables & $(\mathrm{T} 1)$ & $(\mathrm{T} 2)$ & $(\mathrm{T} 3)$ \\
\hline Built in1990s & $0.145^{* * * *}$ & $-0.156^{* * *}$ & $-0.196^{* * *}$ \\
& {$[0.0124]$} & {$[0.0137]$} & {$[0.0149]$} \\
Built in1980s & $0.0459^{* * *}$ & $-0.126^{* * *}$ & $-0.133^{* * *}$ \\
Built in1970s & {$[0.00959]$} & {$[0.0120]$} & {$[0.0130]$} \\
& $0.177^{* * *}$ & 0.0118 & $0.0445^{* * *}$ \\
Square Feet ${ }^{\mathrm{a}}$ & {$[0.0139]$} & {$[0.0133]$} & {$[0.0146]$} \\
& & $0.158^{* * *}$ & $0.189^{* * *}$ \\
Central air conditioning & & {$[0.00341]$} & {$[0.00381]$} \\
& & $0.0980^{* * *}$ & -0.00343 \\
Constant & & {$[0.0147]$} & {$[0.0157]$} \\
& $2.833^{* * *}$ & $2.928 * *$ & $2.681^{* * *}$ \\
Random effects & {$[0.00858]$} & {$[0.00963]$} & {$[0.0108]$} \\
Controls for Temperature Response & Yes & Yes & Yes \\
Observations & No & No & Yes \\
Number of aidid long & $5,625,517$ & $5,625,517$ & $5,625,517$ \\
Robust standard errors in brackets & 118,252 & 118,252 & 118,252 \\
$* * * p<0.01,{ }^{* *} p<0.05,{ }^{*} p<0.1$ & & & \\
\hline
\end{tabular}

**** represent $10 \%, 5 \%$, and $1 \%$ statistical significance, respectively. Robust standard errors clustered at the ZIP9-level. Temperature response controls include square feet, central air conditioning, and vintage dummies interacted with the quadratic degree day parameterization.

a The square feet variable has been demeaned and rescaled by the population standard deviation. 
Table 6

Estimation results, Differences across vintage for total usage with additive price controls, assessor's data. Dependent variable is $\ln \left(K W H \_p e r d a y\right)$.

\begin{tabular}{|c|c|c|c|c|}
\hline Variables & (I) & (II) & (III) & (IV) \\
\hline \multirow[t]{2}{*}{ CDD } & 0.034 & 0.034 & 0.034 & 0.034 \\
\hline & 0.001 & 0.001 & 0.001 & 0.001 \\
\hline \multirow[t]{2}{*}{ sqCDD } & 0.000102 & $9.09 \mathrm{E}-05$ & $9.37 \mathrm{E}-05$ & 0.000107 \\
\hline & 0.0000265 & 0.0000267 & 0.0000267 & 0.0000265 \\
\hline \multirow[t]{2}{*}{ Built in $1990 \times \mathrm{CDD}$} & 0.014 & 0.014 & 0.014 & 0.014 \\
\hline & 0.001 & 0.001 & 0.001 & 0.001 \\
\hline \multirow[t]{2}{*}{ Built in $1980 \times$ CDD } & 0.016 & 0.016 & 0.016 & 0.016 \\
\hline & 0.001 & 0.001 & 0.001 & 0.001 \\
\hline \multirow{2}{*}{ Built in $1970 \times$ CDD } & 0.014 & 0.014 & 0.014 & 0.013 \\
\hline & 0.001 & 0.001 & 0.001 & 0.001 \\
\hline \multirow[t]{2}{*}{ Built in $1990 \times$ sqCDD } & -0.000151 & -0.000152 & -0.000152 & -0.000153 \\
\hline & 0.0000367 & 0.0000369 & 0.0000368 & 0.0000367 \\
\hline \multirow{2}{*}{ Built in $1980 \times$ sqCDD } & -0.000267 & -0.000267 & -0.000267 & -0.000268 \\
\hline & 0.0000303 & 0.0000304 & 0.0000304 & 0.0000303 \\
\hline \multirow[t]{2}{*}{ Built in $1970 \times$ sqCDD } & -0.000487 & -0.000482 & -0.000479 & -0.000468 \\
\hline & 0.0000525 & 0.0000527 & 0.0000527 & 0.0000525 \\
\hline \multirow{2}{*}{ In(average price) (territory) } & & & & -0.606 \\
\hline & & & & 0.0415 \\
\hline \multirow{2}{*}{ ln(average price) (individual) } & & & -0.0979 & \\
\hline & & & 0.0235 & \\
\hline \multirow[t]{2}{*}{$\ln ($ monthly price) (individual) } & & -0.0698 & & \\
\hline & & 0.0167 & & \\
\hline Year dummies & Yes & Yes & Yes & Yes \\
\hline Month dummies & Yes & Yes & Yes & Yes \\
\hline Instrumental variables for prices & $\mathrm{n} / \mathrm{a}$ & Yes, 1999 use & Yes, 1999 use & No \\
\hline Observations & 827,111 & 827,111 & 827,111 & 827,111 \\
\hline Number of accounts & 27,209 & 27,209 & 27,209 & 27,209 \\
\hline
\end{tabular}

Standard errors are in second line and are not clustered.

\section{Policy Significance and Potential Mechanisms}

\section{Policy Significance}

The results show that, in Riverside County, the cumulative temperature response for buildings has been stronger for newer buildings (1980s and 1990s) than for older buildings (1970s and pre1970s). This has two main policy impacts, one for load forecasting and one for the impacts of climate change given that the composition of the building stock is changing to something more temperature responsive.

First, in conducting load forecasts, these results suggest that new construction will increase the average temperature response and increase peak load on the hottest days. As a calibration, the population forecasts of RAND (RAND California, 2010) predict an average annual population increases of 2.6\% for Riverside County. Applying this growth to Riverside County and assuming that new construction has the same temperature response as 1990s buildings, Fig. 18 predicts the increase in average temperature response on a $75{ }^{\circ} \mathrm{F}$ day to go from $48.8 \%$ to $52.3 \%$ from today to 2020 . Peak demand will increase proportionately as well. This is comparable to the estimated $3.7 \%$ increase in California statewide peak demand due to a $1.9{ }^{\circ} \mathrm{C}$ increase in temperature as estimated by Baxter and Calandri (1992). 
Looking at the issue of air conditioning statewide potentially could have an even greater effect. This is because coastal areas have historically had a lower amount of air conditioning, but the CEC revised forecast commented that there was an unexpected increased air conditioner saturation in cooler areas. Tables 7 and 8 present air conditioning saturation for old versus new housing by forecast climate zones from KEMA-XENERGY (2004) data and detailed breakdown for Riverside. Fig. 19 gives a map of the zones. Coastal areas that have very low ownership of air conditioners for older buildings have dramatically increased air conditioner ownership for newly built buildings.

Second, climate change impacts will be exacerbated with the increased temperature response from newer houses. Using the same calculation as given in Fig. 18 above, I can predict the difference in climate change impacts adjusting for the estimate that new buildings are more temperature responsive. In 2050, Riverside's population is predicted to more than double. For a $5^{\circ} \mathrm{F}$ increase due to climate change, temperature response will be about 2-3\% higher with the addition of new buildings compared to the current building stock.

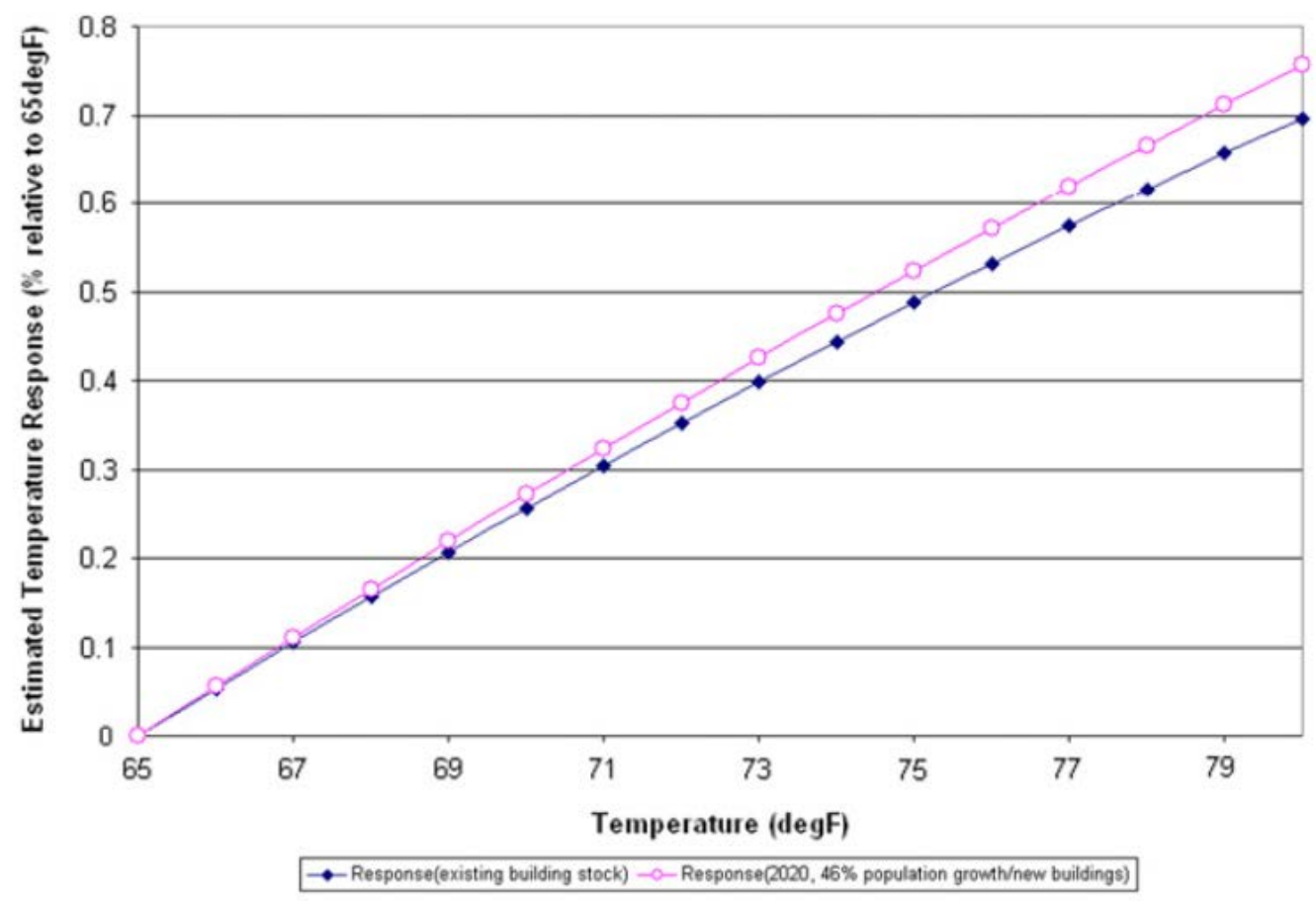

Figure 18 Simulation of Riverside average temperature response in 2020, with and without new building stock. Source: author's calculations. 
Table 7

Comparison of air conditioning saturation by climate zone for old and new homes. Source: RASS 2004.

\begin{tabular}{|c|c|c|c|c|c|}
\hline \multirow[t]{2}{*}{ Zone } & \multirow[t]{2}{*}{ Geography } & \multicolumn{2}{|l|}{ Central air } & \multicolumn{2}{|c|}{ Central or room air } \\
\hline & & $1990 \$(\%)$ & pre1970s (\%) & 1990 s (\%) & pre1970s (\%) \\
\hline 1 & Inland & 56 & 23 & 63 & 37 \\
\hline 2 & Inland & 96 & 55 & 97 & 78 \\
\hline 3 & Inland & 93 & 61 & 95 & 79 \\
\hline 4 & Coastal & 69 & 30 & 72 & 41 \\
\hline 5 & Coastal & 27 & 4 & 29 & 8 \\
\hline 7 & Inland & 93 & 59 & 93 & 73 \\
\hline 8 & Coastal & 77 & 21 & 80 & 32 \\
\hline 9 & Inland & 84 & 39 & 85 & 59 \\
\hline $10^{*}$ & Inland & 94 & 53 & 96 & 76 \\
\hline 11 & Coastal & 60 & 12 & 68 & 25 \\
\hline 12 & Coastal & 75 & 51 & 82 & 81 \\
\hline 13 & Coastal & 68 & 22 & 69 & 32 \\
\hline
\end{tabular}

Note: Zone refers to Forecast Climate Zones as determined by the California Energy Commission. Zone 10 includes Riverside County. A map of the zones is given in Fig. 19.

Table 8

Comparison of air conditioning saturation by vintage in forecast climate zone 10 . Source: RASS 2004.

\begin{tabular}{llcl}
\hline Vintage & Central air (\%) & Room air (\%) & Central or Room (\%) \\
\hline Pre1970s & 53 & 22 & 76 \\
1970 & 80 & 9 & 88 \\
1980 & 89 & 2 & 91 \\
1990 & 94 & 1 & 96 \\
\hline
\end{tabular}

Note: Forecast Climate Zone 10 includes Riverside County.

\section{Potential Mechanisms}

As previously discussed, it is not possible to separate out the mechanism of the vintagedifferentiated temperature response. The heterogeneity by vintage was first estimated, and then controls for observables were included, which captured some of the heterogeneity. The remaining temperature response is from the other factors. ${ }^{25}$ One of the remaining factors that are part of the vintage temperature response coefficients were policy developments. This would include building standards implemented in 1975, 1979, 1984, and 1992 and appliance standards implemented in 1978 and 1987.

After controlling for differences in air conditioning, the remaining differences across households of different vintages is smaller and depends on the specification used. In the main log specification with controls for central air conditioning ownership, new buildings had statistically significantly higher temperature response by a small amount (Fig. 11). Using a level specification and restricting the sample

\footnotetext{
${ }^{25}$ This relies on the assumption that the other factors are uncorrelated. Otherwise, the included controls would pick up other factors through correlation with omitted variable.
} 
to houses of similar size, new homes performed better, but not statistically significantly so (See

Appendix B, Fig. 15).

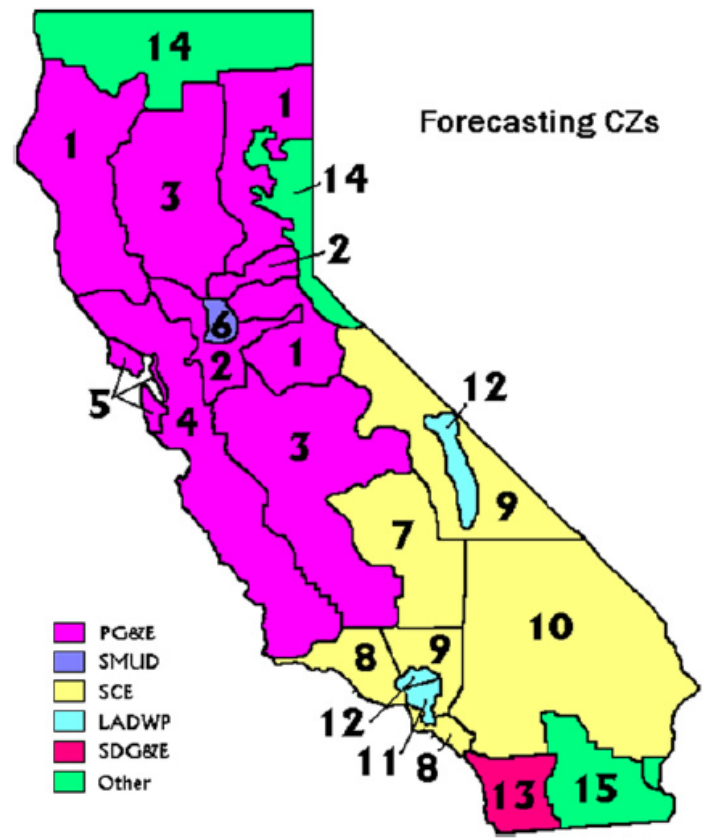

Figure 19 California Energy Commission forecast climate zones. Source: California Energy Commission (2007), page 24.

Table 9

Savings from building standards in 2005 and the implied reduction in temperature response. Source: California Energy Commission reports, author's calculations.

\begin{tabular}{lclll}
\hline Standard & $\begin{array}{l}\text { Estimated savings } \\
(\mathrm{GWH})\end{array}$ & $\begin{array}{l}\text { Savings as percent } \\
\text { of total load (\%) }\end{array}$ & $\begin{array}{l}\text { Statewide population } \\
\text { increase since standard (\%) }\end{array}$ & $\begin{array}{l}\text { Implied impact on temperature } \\
\text { response (cumulative standards) }\end{array}$ \\
\hline Building standard 1992 & 310.7 & 0.4 & 15 & -34 to $-56 \%$ \\
Building standard 1984 & 1074.8 & 1.3 & 29 & -31 to $-53 \%$ \\
Building standard 1979 & 878.7 & 1.1 & 36 & -25 to $-45 \%$ \\
Building standard 1975 & 3166.9 & 3.8 & 41 & -20 to $-38 \%$ \\
\hline
\end{tabular}

Notes: These values include only the top five utilities: PG\&E, SDG\&E, SCE, LADWP, and SMUD. These utilities supply electricity to a wide majority of the state's population. Total residential load is $83,600 \mathrm{GWH}$ for these utilities. To interpret columns 4 and 5 in the second to last row, $36 \%=($ change in population from 1979 to 2005)/(population in 2005) and from $-25 \%$ to $-45 \%$ is the implied percent reduction from all standards prior to and including the 1979 standards. The calculation range is given by a low and high assumption, 0.1 and 0.25 , of the proportion of load that is temperature response. An adjustment factor of $50 \%$ was also used to crudely account for the fact that growth has been faster in hotter inland areas and that new homes are larger. These numbers should be treated as speculative because the details of how the estimated savings were calculated are not fully known beyond that which is described in the two CEC reports referenced in the text of my paper.

Engineering estimates provide a prediction of the impact of buildings standards absent any other changes. Building standards have also varied by vintage and are predicted to reduce temperature response significantly by $34-56 \%$ for new versus old buildings. The CEC identifies four significant changes in building standards and estimates the savings from those standards with engineering models (Marshall and Gorin, 2007; Abrishami et al., 2005). I summarize and report the savings from in Table 9. Total load reduction is about $6 \%$ from engineering estimates. However, to make this result comparable 
to my estimates, two adjustments must be considered. First, building standards only affect new construction and major renovation; these are represented in the fourth column which has the population increase since the standard went into effect as a proportion of the current population. Also, building standards only affect the temperature response component of electricity use. I calculate the implied reduction in temperature response from each building standard in the last column.

\begin{tabular}{|c|c|c|c|c|}
\hline Building vintage & Morning & Day & Evening & Night \\
\hline Pre1970s & 0.49 & 0.71 & 0.73 & 0.46 \\
\hline 1970 & 0.54 & 0.69 & 0.76 & 0.5 \\
\hline 1980 & 0.51 & 0.66 & 0.76 & 0.47 \\
\hline 1990 & 0.52 & 0.72 & 0.82 & 0.52 \\
\hline
\end{tabular}

$N$ is about 300 . Sampling error is about 0.03 for each cell.

The juxtaposition of large predicted decrease in temperature response due to building standards and my research finding of overall increasing temperature response across vintages suggests that other factors have had a large positive effect on temperature response in new houses. There are multiple potential mechanisms, none of which the data can separate out. Behavioral responses, such as those driven by the rebound effect (Greening et al., 2000) can increase temperature response. This would mean that part of the increase is due to an increase in comfort from using more cooling services. New buildings may differ in their thermal design in that they may have taller ceilings, fewer trees, less passive shading, more structural complexity, or a higher window-to-wall ratio; all of which may increase the electricity needed to cool a building. It is also possible that there is sorting, where people who favor more cooling services are more likely to live in new buildings. Another possibility is that standards may not have been as effective as they have claimed, following the logic of Joskow and Marron (1992). These are factors that need to be carefully considered when designing and evaluating of building standards.

Table 11

Average thermostat set points (in ${ }^{\circ} \mathrm{F}$ ) conditional on central air conditioning on by vintage and time of day.

\begin{tabular}{lllll}
\hline Building vintage & Morning & Day & Evening & Night \\
\hline Pre1970s & 74.5 & 74.4 & 74.5 & 74.4 \\
1970 & 74.8 & 75.0 & 75.1 & 74.7 \\
1980 & 74.4 & 74.9 & 74.6 & 74.3 \\
1990 & 74.8 & 74.7 & 74.5 & 74.7 \\
\hline
\end{tabular}

Standard deviation is about $3^{\circ} \mathrm{F}$ for each cell.

Some auxiliary information suggests that sorting plays a limited role in explaining the results of higher temperature response in new buildings. Using data from KEMA-XENERGY (2004) for homes in this 
region, Table 10 shows the self- reported proportion of homes who turn on their air conditioning by vintage and time of day, and Table 11 the self-reported average thermostat set point conditional on having central air conditioning on by vintage and time of day. The newer buildings tend to turn on their air conditioner slightly more often, but the set point of the thermostat is not very different across vintages. This data cannot be used in the regression framework because it is available only for large areas whereas assessor and census data were available for small areas.

This research also presents a puzzle about the causes of the Rosenfeld Curve, shown in Fig. 1. Since the mid 1970s, per capita electricity consumption for California has been flat while it has increased $50 \%$ for the United States. The breakpoint in the 1970 s coincided with the establishment of aggressive energy efficiency policies. The Rosenfeld Curve coupled with engineering estimates suggest that California's policies have been very effective, but this research suggests that, in terms of temperature response, the net effect has been that newer buildings increase temperature electricity use more than older ones in response to high temperatures in Riverside County, one of California's hottest counties. Several other drivers (most notably, population growth biased toward hotter areas which have higher electricity use) would also increase aggregate per capita electricity consumption. The resulting puzzle is why California has had a flat per capita electricity profile despite these drivers that would strongly push electricity use upwards. Future research should look at patterns of population growth, housing size (square footage), and changes in heating fuel in addition to the heretofore studied differences between new and old residential buildings in temperature response. This would present a fuller picture of the multiple drivers that have resulted in California's flat electricity use profile.

\section{Conclusion}

The contribution of this paper is to focus on the relationship between building vintage and temperature response in residential buildings in part of California. The main finding is that temperature response for buildings varies by vintage: new buildings (1970-2000) have a statistically significantly higher temperature response (i.e., use more electricity in response to higher temperature) than old buildings (pre1970). This is robust to many specifications. The cumulative positive effect for temperature response in new buildings means that increased air conditioning ownership and other factors have outweighed other energy-saving impacts, such as building standards applied to new residential buildings.

This result has two main implications, one for electricity demand forecasting and one for climate change impacts. First, since new residential buildings have higher temperature response, this means 
that the average temperature response is expected to go up as new buildings are added. Peak electricity load will also increase, even with climate held constant. Second, if temperatures increase due to climate change, the new residential buildings will exacerbate the increase in peak load.

\section{Acknowledgements}

University of California Energy Institute (UCEI) provided financial support, access to utility data, and an invaluable intellectual environment to pursue this research. I thank Max Auffhammer, Peter Berck, Carl Blumstein, Severin Borenstein, Lucas Davis, Meredith Fowlie, Koichiro Ito, Carla Peterman, Nehemiah Stone, Sofia Villas-Boas, and David Zilberman for many excellent discussions. Excellent feedback came from participants at UCEI Camp, UCEI Seminar, ARE Departmental Seminar, NBER Summer Institute (EEE), the California Energy Commission, the Maastricht University conference on Green Buildings, PG\&E, and USAEE/ IAEE 2010 Conference. Financial support from the California Energy Commission is gratefully acknowledged. Any remaining errors are mine alone.

\section{Appendix A. Total Electricity vs Temperature Response}

This appendix provides estimates that compare the differences in the total electricity use across households of different vintages. Note that because the variation in age of housing does not vary over time, this precludes the use of household fixed effects. Vintage differences will include not only building differences but also other differences across households such as increases in the amount of appliances or differences in use.

Regression results are shown below using a random effects specification with clustering at the ZIP9 level in Table 5. The first column shows that newer buildings have larger electricity usage with no clear pattern across decades. The second column two adds a control variable for square footage. Size increases total electricity use, as expected, but the estimates have 1990s and 1980s buildings using less energy after controlling for size, whereas 1970s buildings use slightly more than pre1970s buildings. The third column adds controls for temperature interacted with all variables; the signs of the vintage coefficients are unchanged.

Though interesting empirical regularities, the coefficients on the vintage variables are hard to interpret. They can be rationalized both by increasing efficiency of appliances in new buildings or fewer appliances in new buildings of comparable size. 
It is important to note that newer buildings have a larger temperature invariant component (Column T1), which means that the same percentage increase in new buildings and old buildings (due to temperature difference) also means a higher change in kWh for the new buildings.

\section{Appendix B. Functional Form}

The function form used in electricity regressions varies across studies, with the literature split between have $\ln \left(\mathrm{kWh}_{\text {useperday }}\right)$ (dubbed "In") or $\mathrm{kWh}_{\text {useperday }}$ (dubbed "levels") as the LHS variable. In many cases, the choice is ad hoc, justified on the grounds that the In specification compares percent changes across observations which roughly controls for size. In KEMA-XENERGY (2004), a conditional demand analysis framework is used that is motivated by the concept of summing up the loads of each appliance separately. In this case, levels are the appropriate regress and temperature response is scaled by some measure of the size of a house.

First, I present a mathematical justification for the In specification. Second, I present some results using levels as the regress and after making appropriate adjustments. The results across vintage are similar:

(8)

kwhperday $_{i t}=$ base $_{i}+$ heat $_{i t}+$ cool $_{i t}$

(9)

kwhperday $_{i t}=$ base $_{i}+f($ weather $) \times f($ size $) \times f($ other $)$

kwhperday $_{i t}=$ base $_{i}+Z$

$\ln \left(\right.$ kwhperday $\left._{i t}\right)=\ln \left(\right.$ base $\left._{i}\right)+\frac{1}{\text { base }_{i}} * Z$

via Taylor approximation around $Z=0$

(12)

$\ln \left(\right.$ kwhperday $\left._{i t}\right)=\ln \left(\right.$ base $\left._{i}\right)+\frac{1}{\text { base }_{i}} * f($ weather $) \times f($ size $) \times f($ other $)$

assuming $\frac{f\left(\text { size }_{i}\right)}{\text { base }_{i}}=Q$, a constant 
(13)

$\ln \left(\right.$ kwhperday $\left._{i t}\right)=\ln \left(\right.$ base $\left._{i}\right)+Q * f($ weather $) \times f($ other $)$

The derivation above begins with a partition of energy use into a base usage that is temperature and time invariant followed by heating and cooling loads that vary by time through weather's variation over time. The next step takes the natural log and then expands the expression via a Taylor expansion. Under the maintained hypothesis that a function of size enters multiplicatively and that the ratio of base usage to the function of size is constant, size can then be omitted. Intuitively, this specification assumes that percent changes of bills are the comparable metric across buildings of different size. The fother) term would include vintages, housing characteristics, and household characteristics. ${ }^{26}$

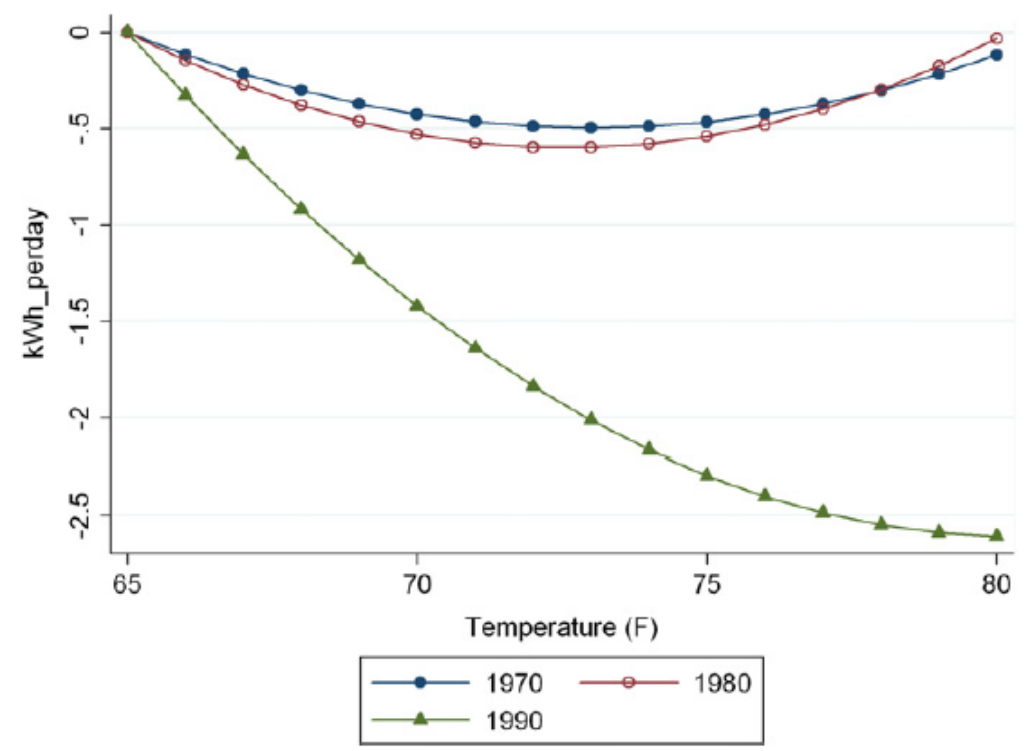

Figure 20 Estimation results, difference in temperature response with CDD and HDD parameterization, assessor's data, by vintage. Dependent variable is KWH_perday. This uses the assumption that $f(s i z e)=s q f t$.

\footnotetext{
${ }^{26}$ A reasonable alternative approach would be to use Box-Cox transformations to estimate nonlinearly the impact of size and choosing the model with the best fit.
} 


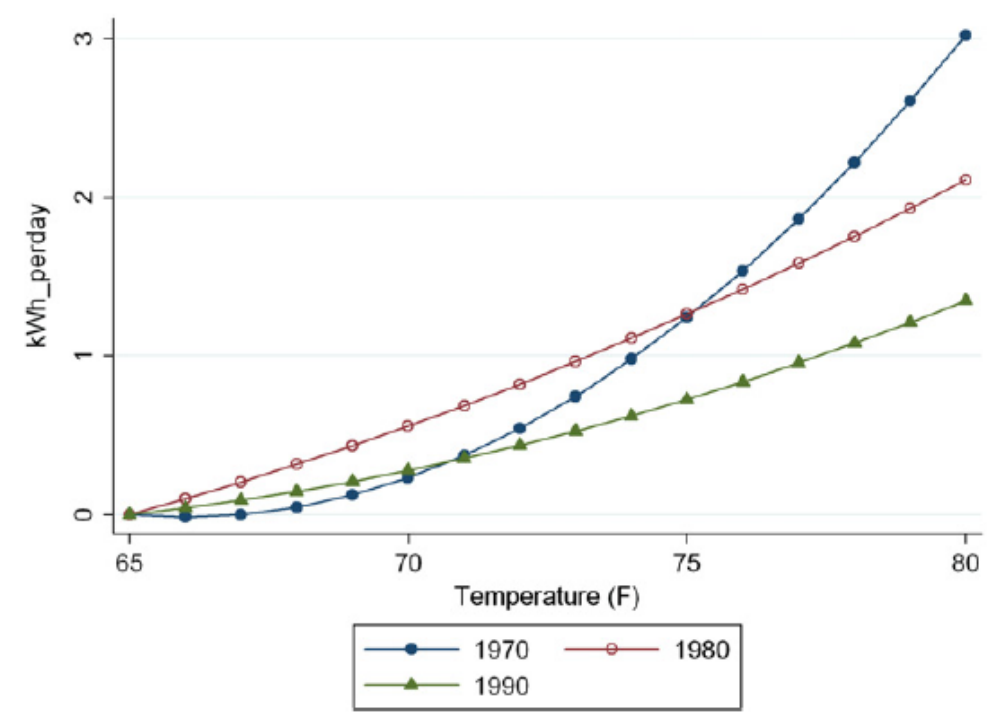

Figure 21 Estimation results, difference in temperature response with CDD and HDD parameterization, assessor's data, by vintage, restricted to sqft in $[1300,1600]$. Dependent variable is KWH_perday. This uses the assumption that $f$ Jsizeb $1 / 4 \mathrm{sqft}$, but for a narrow range of sqft.

Alternatively, one could directly estimate Eq. (9) by choosing a functional form for $f($ weather)x $f($ size $) \mathrm{f}$ (other) when such data is available at a fine spatial resolution. My data at the ZIP9-level, which on average has 5-10 households, is spatially more disaggregated than most other data. Weather was parameterized as a function of CDD and HDD and its squares.

A natural assumption to make is that cooling and heating loads scale by size, so that $f(s i z e)=s q f t$. This turns out to not be a good assumption, as shown below. I first estimate the cumulative temperature response across vintages without other controls as described in the following equation:

$$
k w h \_ \text {useperday }{ }_{i j t}=\sum_{v=1}^{\text {VINTAGES }} V_{j v} *\left(\beta_{1 v} s q f t \times C D D_{i t}+\beta_{2 v} s q f t \times C D D_{i t}^{2}+\beta_{3 v} s q f t \times H D D_{i t}+\beta_{4 v} s q f t \times H D D_{i t}^{2}\right)+\alpha_{i}+\varepsilon_{i t}
$$

The results in Fig. 20 show that new buildings are much less temperature responsive, contrary to other specifications. I then re-estimate this constrained to areas where the sqft variable is between 1300 and 1600 sqft which is a range of sqft with substantial overlap for all vintages. The results in Fig. 21 show that new buildings perform worse, as is expected because they have much more air conditioning. This matches the results established in the main specification. One reason the two results differ is 
because the median of the sqft variable is larger for new houses and cooling loads scale less than proportionately with sqft. Hence, the assumption that $f$ Jsizep $1 / 4$ sqft overcorrects for size. ${ }^{27}$

While still using levels, I estimate a less functionally constrained version of $f($ weather) $\mathrm{f}(\mathrm{size}) \mathrm{x}$ $\mathrm{f}$ (other) in Eq. (9). Size is restricted to sqft between 1300 and 1600. $F($ size $)=\left(\alpha_{0}+\alpha_{1}{ }^{*}\right.$ sqft) which is a first order approximation applied to this narrow range of sqft. A similar first order approximation is used for air conditioning, and vintage is given by an indicator variable, similar to the main specification. The final specification has 64 parameter estimates:

kwhperday $_{i t}=$ base $_{i}+f($ weather $) \times f($ size $) \times f($ other $)$

where

$$
\begin{aligned}
& f(\text { weather })=\gamma_{1} C D D+\gamma_{2} C D D^{2}+\gamma_{3} H D D+\gamma_{4} H D D^{2} \\
& f(\text { size })=\alpha_{0}+\alpha_{1} * \text { sqft } \\
& f(\text { other })=\sum_{v=1}^{\text {VINTAGES }} \delta_{v} * \text { VintageDummy } y_{v} *\left(\delta_{0}+\delta_{\text {CAC }} * \text { CentralAirConditioning }\right)
\end{aligned}
$$

Fig. 15 shows the results of the regression by predicting the value of electricity consumption $k_{w h p e r d a y_{i t}}$, for a reference 1500 sqft house with central air conditioning for each vintage. Because of the large number of covariates, the regression results are omitted. The results show that the 1990s and 1970s buildings may have lower temperature response after controlling for air conditioning and size, but that the difference is not statistically significant. Focusing just on the 1990s buildings, the range of the difference at $75^{\circ} \mathrm{F}$ is - 2 to $\mathrm{p} 1.5 \mathrm{kwh}$ per day. . This translates into an $-8 \%$ to $+6 \%$ difference in temperature response and is the lowest estimate of all specifications run. ${ }^{28}$

\section{Appendix C. Aggregation}

The aggregation issue can be described by referring to the discussion of Blundell and Stoker (2005) which focuses on aggregation issues in demand systems and other scenarios. Aggregation presents biases when the underlying data generating process has cross-terms and there are non-zero

\footnotetext{
${ }^{27}$ KEMA-XENERGY (2004) models cooling load as scaling by external surface area. If a building doubles in size, the external surface area will less than double. For example, a cube on the ground has five external faces (one exposed to the ground), but two cubes side by side only have eight external faces.

${ }^{28}$ This result, run on a sample restricted to a small range of building sqft, is most comparable to the results in Fig. 12 , which has a range from $+4 \%$ to $+12 \%$.
} 
covariances. For example, the following data generating process has no cross-terms and could be estimated by data aggregated spatially across $j$ :

(16)

$y_{i j}=\beta_{0}+\beta_{1} * x_{i j}+\beta_{2} * z_{i j}+\varepsilon_{i j}$

$E_{j}\left[y_{i j}\right]=\beta_{0}+\beta_{1} * E_{j}\left[x_{i j}\right]+\beta_{2} * E_{j}\left[z_{i j}\right]+E_{j}\left[\varepsilon_{i j}\right]$

$$
y_{j}=\beta_{0}+\beta_{1} * x_{j}+\beta_{2} * z_{j}+\varepsilon_{j}
$$

In the presence of a cross term, the aggregation presents bias if there are covariances. In the example below, the relationship between the individual level coefficient, $\beta_{3}$, and the aggregate regression parameter, $\Upsilon_{3}$, is $\beta_{3}=\Upsilon_{3} \times\left(E_{j}\left[x_{i j}\right] * E\left[Z_{i j}\right] / E_{j}\left[x_{i j}{ }^{*} z_{i j}\right]\right)$. The two equal if an only if the covariance, $\operatorname{Cov}\left(x_{i j}, y_{i j}\right)$, is zero:

$y_{i j}=\beta_{0}+\beta_{3} * x_{i j} * z_{i j}+\varepsilon_{i j}$

$E_{j}\left[y_{i j}\right]=\beta_{0}+\beta_{3} * E_{j}\left[x_{i j} * z_{i j}\right]+E_{j}\left[\varepsilon_{i j}\right]$

$$
E_{j}\left[y_{i j}\right]=\beta_{0}+\beta_{3} *\left(E_{j}\left[x_{i j}\right] * E\left[z_{i j}\right]+\operatorname{Cov}\left(x_{i j}, y_{i j}\right)\right)+E_{j}\left[\varepsilon_{i j}\right]
$$

$$
y_{j}=\beta_{0}+\gamma_{3} * x_{j} * z_{j}+\varepsilon_{j}
$$

Aggregation problems are less likely with county assessor's data than with census block group data. County assessor's data is matched at the ZIP9-level, which is about 5-10 households. Hence, it is hoped that covariates in a ZIP9-level are relatively homogeneous in terms of house size, vintage of year built, and ownership of air conditioning. Census block groups, at 300-700 households each are much more likely to have these issues.

I have not done aggregation of bill to the census block or zip code level. Aggregation of all bills within a census block group presents problems if the panel is unbalanced: some bills exist in some 
months but not in others. A large proportion of properties have occupant turnover. If occupant turnover were random, dropping unbalanced observations would not present bias, but it is plausible that certain homes are more likely to have occupant turnover.

\section{Appendix D. Extended Data Discussion}

Building characteristic information comes from two datasets. The first dataset uses ZIP9-level data from county assessor's information. The second dataset uses census block group-level data from the 2000 Census.

The billing data was cleaned. Bills with 25 days or less or 35 days or more were dropped (about $5 \%$ ). Bills with less than $2 \mathrm{kWh} /$ day or more than $80 \mathrm{kWh} /$ day are outliers were also dropped (about 4\%). For the ZIP9 data, assessor's data primarily includes complete records of square footage, year built, and air conditioning ownership for single family homes. Records were dropped if there was more than 10 bedrooms, square footage less than 200 or greater than 10 000, missing ZIP code, or the structure was built before 1850 or after 2000. Many of these were obvious data errors because they contained internally inconsistent values, such as many bedrooms but very little square footage. Census block group information was used to identify areas where more than $95 \%$ of the households were in single family structures and decreases the sample to those areas that satisfy these criteria. Next, at the ZIP9-level, the proportion of houses with central air conditioning, the median structure size, and the proportion of buildings built in each vintage category were attributed to each bill in that associated ZIP9.

For the census block group data, a 1-in-5 subsample of observations was used to enable the estimation to be run on a Linux server with 8 GB of RAM and an Intel Quadcore processor, running Stata 10.0 MP. For the assessor's data, because data was restricted to census block groups with mostly single family homes, data reduction was not needed.

The spatial matching of weather, census block groups, and ZIP9s merits some description. Weather data is available on a $4 \mathrm{~km} \times 4 \mathrm{~km}$ grid. Census block groups are given as polygons. ZIP9s are given as points, but the ZIP9 are actually ranges of street addresses. Typically opposite sides of the street will have different ZIP9s. To describe the matching from the perspective of the bill, the bill's ZIP9 is matched to the census block group and $4 \mathrm{~km}$ by $4 \mathrm{~km}$ grid square that contains the ZIP9 point. 


\section{References}

Abrishami, M., Bender, S., Lewis, K.C., Movassagh, N., Puglia, P., Sharp, G., Sullivan, K., Tian, M., Valencia, B., Videva, D., 2005. Energy Demand Forecast Method Report: Companion Report to the California Energy Demand 2006-2016 Staff Energy Demand Forecast Report. Technical Report, June.

Aroonruengsawat, A., Auffhammer, M., 2009. Impacts of Climate Change on Residential Electricity Consumption: Evidence From Billing Data. California Energy Commission, CEC-500-2009-018-D, March.

Aroonruengsawat, A., Auffhammer, M., Sanstad, A., 2009. The Impact of State Level Building Codes on Residential Electricity Consumption. Technical Report, UC Green Building Conference 2009.

Auffhammer, M., Blumstein, C., Fowlie, M., 2008. Demand-side management and energy efficiency revisited. Energy Journal 29 (3).

Baxter, L.W., Calandri, K., 1992. Global warming and electricity demand: a study of California. Energy Policy 20 (3), 233-244.

Blundell, R., Stoker, T., 2005. Heterogeneity and aggregation. Journal of Economic Literature 43 (2), 347391.

Building Codes Assistance Project. Code Status /bcap-energy.orgS (accessed 7/30/2009), archived.

California Energy Commission, Integrated Energy Policy Report. Technical Report, California Energy Commission.

Costa, D.L., Kahn, M.E., 2010. Why Has California's Residential Electricity Consumption Been So Flat since the 1980s? A Microeconometric Approach, Working Paper \#15978, NBER May.

County of Riverside Assessor's Office, 2010. Property Characteristics - Full; Catalog Code ASPRCHAR, CDROM August.

Deschênes, O., Greenstone, M., 2011. Climate change, mortality and adaptation: evidence from annual fluctuations in weather in the US. American Economic Journal: Applied Economics 3 (4), 152185.

Energy Information Administration, 2007. State Energy Data System www.eia.doe.gov/emeu/states/ seds.htmlS (accessed 7/30/2009), local archive from 2007.

Energy Information Administration, 2009. Residential Energy Consumption Survey (RECS), 2005 /www.eia.doe.gov/emeu/recs/S. Environmental Protection Agency, 2010. U.S. Greenhouse Gas Inventory Report. Technical Report, U.S. Environmental Protection Agency. 
Greening, L.A., Greene, D.L., Difiglio, C., 2000. Energy efficiency and consumption - the rebound effect a survey. Energy Policy 28 (6-7), 389-401.

Hirst, E., 1990. Progress and potential in evaluating energy efficiency programs. Evaluation Review 14 (1), 192-205.

Horowitz, M.J., 2007. Changes in electricity demand in the United States from the 1970s to 2003. Energy Journal 28 (3), 93-119.

Ito, K., 2010. Do Consumers Respond to Marginal or Average Price? Evidence from Nonlinear Electricity Pricing. Technical Report November.

Jacobsen, G.D., Kotchen, M.J., 2010. Are Building Codes Effective at Saving Energy? Evidence From Residential Billing Data in Florida, Working Paper \#16194, NBER May.

Joskow, P.L., Marron, D.B., 1992. What does a negawatt really cost? Evidence from utility conservation programs. Energy Journal 13 (4), 41-74.

Joskow, P.L., Marron, D.B., 1993. What does utility-subsidized energy efficiency really cost? Science 260 (5106), 281-370

KEMA-XENERGY, 2004. California Statewide Residential Appliance Saturation Survey: Final Report. Technical Report, California Energy Commission, June.

Larsen, B.M., Nesbakken, R., 2004. Household electricity end-use consumption: results from econometric and engineering models. Energy Economics 26 (2), 179-200.

Loughran, D.S., Kulick, J., 2004. Demand-side management and energy efficiency in the United States. The Energy Journal 25 (1), 19-43.

Marshall, L., Gorin, T., 2007. California Energy Demand 2008-2018 Staff Revised Forecast. Technical Report, November.

Nadel, S.M., Keating, K.M., 1991. Engineering estimates versus impact evaluation results: how do they compare and why? In: Energy Program Evaluation: Uses, Methods, and Results, Proceedings of the 1991 International Energy Program Evaluation Conference 1991.

RAND California, 2010.County population estimates, /http://ca.rand.org/stats/statlist.htmlS (accessed September 23, 2010).

Reiss, P.C., White, M.W., 2008. What changes energy consumption? Prices and public pressures. RAND Journal of Economics 39 (3), 636-663.

Schlenker, W., Roberts, M., 2009. Nonlinear temperature effects indicate severe damages to U.S. crop yields under climate change. Proceedings of the National Academy of Sciences USA 106 (37), 15594-15598. 
Sudarshan, A., Sweeney, J., 2008. Deconstructing the Rosenfeld Curve. Stanford University, Stanford, CA. Online at/piee.stanford.edu/cgibin/docs/publications/sweeney/Deconstructing the RosenfeldCurve.pdfS.

United States Census Bureau, 2009. Census 2000 Summary File 3 ASCII text data files

/http://www.census.gov/support/SF3ASCII.htmIS (accessed July2009). 